\title{
Molecular simulation and microtextural characterization of quartz dissolution in sodium hydroxide
}

\author{
Abdullah Musa Ali ${ }^{1}$ (D) Noorhana Yahya ${ }^{2} \cdot$ Abubakar Mijinyawa $^{1} \cdot$ Mohammed Yerima Kwaya $^{1} \cdot$ Surajudeen Sikiru ${ }^{2}$
}

Received: 10 January 2020 / Accepted: 20 June 2020 / Published online: 29 June 2020

(c) The Author(s) 2020

\begin{abstract}
This study uses empirical experimental evidence and Material Studio simulations to explain the interaction of sodium hydroxide $(\mathrm{NaOH})$ with quartz. Density functional theory (DFT) calculations were carried out using the Cambridge Serial Total Energy Package. In addition, quartz grains subjected to dissolution in $\mathrm{NaOH}$ were characterized using scanning electron microscopy. The so-called O-middle termination in the quartz tetrahedron structure, typified by a solitary exposed oxygen atom at the surface, is the most susceptible $\mathrm{SiO}_{2}$ terminations to $\mathrm{NaOH}$ attack, as it is associated with the lowest surface energy. The adsorption energy values are $-1.44 \mathrm{kcal} / \mathrm{mol}$ and $-5.90 \mathrm{kcal} / \mathrm{mol}$ for a single atom layer and five-layered atomic structure, respectively. The DFT calculation reveals intramolecular energy is the dominant adsorption energy, followed by a weak van der Waals energy. The $\mathrm{NaOH}$ adsorbed on quartz (001) surface constitutes a lower band gap of $0.138 \mathrm{eV}$ compared to cleaved quartz $(001)$ surface $(0.157 \mathrm{eV})$. In addition, the energy range of $\mathrm{NaOH}$ adsorbed on quartz is wider $(-50$ to $10 \mathrm{eV}$ ), compared to (001) quartz ( -20 to $11 \mathrm{eV}$ ). The dissolved quartz showed the precipitation of sorbed silicate phases due to incongruent reactions, which indicates new voids and etch pits can be created through the cleaving of the sodium silicates sorbed into the quartz surface. The adsorption energy for $\mathrm{NaOH}$ interactions with reservoir sandstone was significantly higher compared to the solitary crystal grains, which can be attributed to the isotropic deformation of a single crystal, and non-uniform deformations of adjacent grains in granular quartz of sandstone reservoir. It can be inferred that exposure to $\mathrm{NaOH}$ will affect the structure and reactivity of quartz. The quartz surface textural study indicates that dissolution of crystalline (granite) and clastic rocks (sandstone) is critical to the development of voids, which will improve permeability by providing channels and routes for the passage of hydrothermal and reservoir fluids.
\end{abstract}

Keywords Quartz dissolution · Sodium hydroxide $(\mathrm{NaOH}) \cdot$ Absorption energy $\cdot$ Density of states $\cdot$ Microtextural features

\section{Introduction}

Quartz is an abundant silicate mineral that plays a significant part in geological studies, as oxygen and silicon are the key elements of Earth's crust. Understanding the kinetics of quartz-water reaction is critical in elucidating a number of important topics in geochemistry such as soil formation and degradation, chemical weathering, enhanced porosity in reservoirs via dissolution and $\mathrm{CO}_{2}$

Abdullah Musa Ali

alicorp@yahoo.com

1 Department of Geology, Bayero University Kano (BUK), Kano, Nigeria

2 Fundamental and Applied Sciences Department, Universiti Teknologi PETRONAS, 32610 Seri Iskandar, Perak, Malaysia sorption (White and Brantley 1995; White et al. 2001; Zhang and Liu 2014). The dissolution of quartz mineral controls the formation of voids in aquifers and sandstone reservoirs, transport and sorption of noxious waste, trace metals and $\mathrm{CO}_{2}$ and ore formation (Brantley 2004). Quartz dissolution is crucial to chemical reactions that control the porosity, permeability and sorption capacity of sandstone reservoirs (Schott and Oelkers 1995; Lasaga and Luttge 2001; Brantley 2008). In geoscience, deciphering the reactions that control the dissolution of quartz is imperative since developing secondary pores in siliciclastics is a constraint in the exploitation of precious metals and hydrocarbon (HC) recovery (Smith and Steele 1984). The precipitates derived from pore waters following dissolution reactions may plug/block in situ pore spaces, thus impeding HC recovery efforts. Accordingly, the porosityincreasing route of dissolving labile framework grains in 
sandstones is dependent on the dissolution of quartz. The structure-property of quartz is also intrinsically relevant for various technological applications such as pressure gauges, oscillators, resonators and wave stabilizers (Bosak et al. 2011).

Quartz is known to dissolve in alkali solutions such as $\mathrm{NaOH}$. Hence, subjecting quartz to alkali dissolution is a viable approach to expanding existing pores and creating new ones. Moreover, the injection of alkali fluids into HC reservoirs improves recovery by lowering the interfacial tension (IFT) of oil via a blend of alkali chemicals and surfactants (Hornof et al. 2000). Alkali reaction with siliciclastics between the injection and production wells can expand the pores and improve pore connectivity along the flood path (Labrid and Duquerroix 1991; Bagci et al. 2000). $\mathrm{NaOH}$ reduces the interfacial tension (IFT) considerably by developing in situ surfactants (Wang et al. 2010). However, despite the several experimental studies (Rimstidt 2015; Dove 1999) on quartz dissolution in $\mathrm{NaOH}$, few studies have researched molecular-level elucidation of the dissolution mechanism with regard to singular $\mathrm{SiO}_{2}$ grains (Wang et al. 2018; Yanina et al. 2006). Deciphering this interaction using density functional theory (DFT) modelling is vital since traditional microscopic and spectroscopic analyses have not been completely successful in providing comprehensive structural properties of the quartz surface at atomic/molecular level due to their restricted resolutions or precisions.

Therefore, this study is an attempt to use simulation (DFT calculations) carried out in Material Studio software to explain the interaction of $\mathrm{NaOH}$ with single crystalline $\mathrm{SiO}_{2}$ via state-of-the-art ab initio calculations (Nilges et al. 2009). The surface chemical activities of quartz are closely related to its surface structure and properties (Bosak et al. 2011). Thus, studies on the surface features of cleaved quartz with the use of computational techniques unanimously agree that the (001) surface is the thermodynamically predominant plane (Dove and Rimstidt 1994; Yang and Wang 2006; Chen et al. 2008; Wander and Clark 2008). The quartz crystal will be cleaved along the 001 plane for $\mathrm{NaOH}$ adsorption. DFT calculations will then be carried out on the cleaved surface. This study will also provide morphological evidence of $\mathrm{NaOH}$-dissolved quartz surface. In addition to the dissolution of a solitary quartz crystal, this paper provides a realistic mechanism of alkali-induced quartz dissolution, which was achieved by creating a model of reservoir sandstone that integrates quartz, feldspar, clay, oil and brine into a single unit. This approach considers reservoir minerals and fluids that were disregarded in previous simulations and experimental studies of quartz dissolution. Thus, the novelty of this research is based on simulating a polymineralic scenario (reservoir sandstone) for quartz dissolution.

\section{Mechanism of quartz dissolution}

Quartz comprises Si-O-Si linkage structures; however, the surface terminations are composed of hydrophilic hydroxyl groups (Nangia and Garrison 2008). The metal oxide is hydrolysed in the presence of $\mathrm{H}_{2} \mathrm{O}$ to yield the surface hydroxide ligands (-Si-OH) (Degen and Kosec 2000; Yang et al. 2004). The surface ligands may then develop into a charged one through reaction with hydroxyl $\left(\mathrm{OH}_{-}\right)$ or hydronium $\left(\mathrm{H}^{+}\right)$ions due to the amphoteric characteristic of surface reactions. The quartz reacts with water via two contrasting processes: physical adsorption (Eq. 1) and chemical dissolution (Eq. 2). Physiochemical adsorption of $\mathrm{H}_{2} \mathrm{O}$ molecules onto the quartz's surface via hydrogen bonding leads to the formation of stable tessellated arrangements (Goumans et al. 2007; Nangia et al. 2007). Protons are adsorbed on surface of the $\mathrm{Si}-\mathrm{OH}$ under acidic conditions to form a positively charged surface (Eq. 1), whereas under alkali $\mathrm{pH}$ conditions, the surface of $\mathrm{Si}-\mathrm{OH}$ deprotonates to induce a negatively charged surface (Eq. 2). Furthermore, $\mathrm{Si}-\mathrm{OH}$ adsorption, in addition to other charges present on the metal oxide surface, produces deprotonated/hydroxylated metal species in the solution:

$\mathrm{Si}-\mathrm{OH}+\mathrm{H}^{+} \leftrightarrow \equiv \mathrm{Si}-\mathrm{OH}_{2}^{+}$

$\mathrm{Si}-\mathrm{OH}+\mathrm{OH}^{-} \leftrightarrow \mathrm{Si}-\mathrm{O}^{-}+\mathrm{H}_{2} \mathrm{O}$

Generally, the hydrolysis of quartz can involve four possible dissolution mechanisms (Nangia et al. 2007; Bickmore et al. 2008; Pelmenschikov et al. 2000): (a) hydrolysis of the $\mathrm{Si}$ centre by water $\left(\mathrm{H}_{2} \mathrm{O}\right)$ to form a 5-coordinated specie, accompanied by weakening of the contiguous linking/bridging bond (Fig. 1a); (b) the hydrolysis of Si centre by $\mathrm{H}_{2} \mathrm{O}$ and rupture of the neighbouring bridging bond, but here the reaction is catalysed by $>\mathrm{SiO}^{-}$(Fig. 1b); (c) elimination of the $\mathrm{H}^{+}$from $>\mathrm{SiOH}$ by $\mathrm{OH}-$, thus forming $\mathrm{H}_{2} \mathrm{O}$, which moves on to hydrolyse the Si centre in a way similar to the earlier scenario, i.e. mechanism 2 (Fig. 1c); and (d) protonation of a bridging $\mathrm{O}$ by $\mathrm{H}_{3} \mathrm{O}^{+}$, followed by the hydrolysis of a contiguous $\mathrm{Si}$ centre by $\mathrm{H}_{2} \mathrm{O}$, formation of a 5-coordinated specie and weakening of the bridging bond (Fig. 1d). Nonetheless, all the dissolution mechanisms involve the interaction of water with quartz surface, resulting in the cleaving of the siloxane ( $\mathrm{Si}-\mathrm{O}-\mathrm{Si}$ ) bonds to form hydrolysed species. Therefore, surface hydroxyl is key to this quartz dissolution process (Bickmore et al. 2008; Pelmenschikov et al. 2000; Xiao and Lasaga 1996). The -OH group may be physically sorbed to several sheets of polar $\mathrm{H}_{2} \mathrm{O}$ molecules.

Numerous mechanisms have been developed to explain the influence of basic/alkali ions on quartz dissolution. Rate limiting hydrolysis steps reported in a related study (Bickmore et al. 2008) proposed that $\mathrm{OH}$ ions first hydrolyse a 

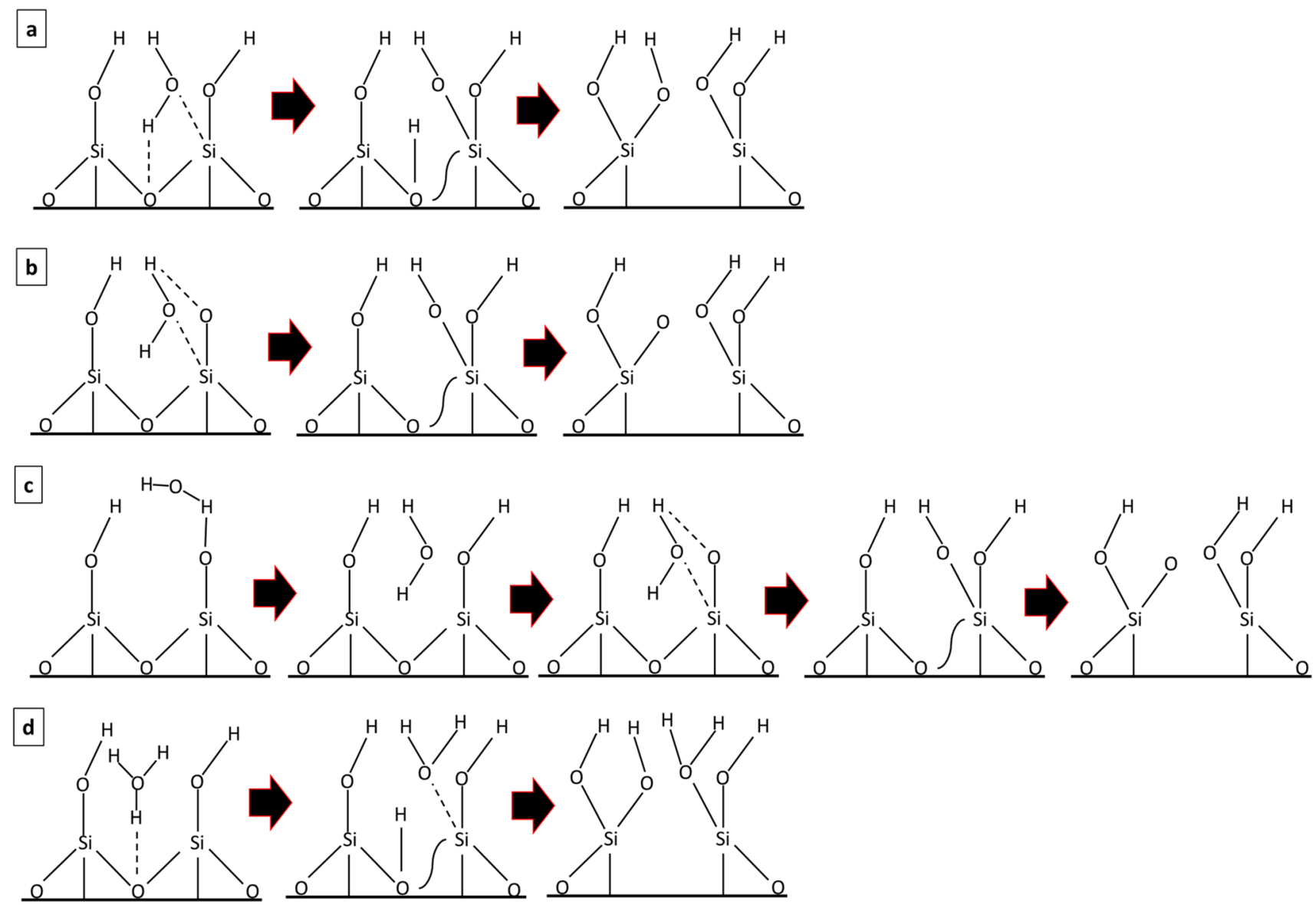

Fig. 1 Graphical representation of four possible hydrolysis mechanisms of quartz dissolution (Bickmore et al. 2008; Pelmenschikov et al. 2000; Xiao and Lasaga 1996)

Si centre, creating a 5-coordinated structure and weakening the neighbouring/adjacent bridging bond (Fig. 2a). Similarly, in the case of $\mathrm{NaOH}$, the $-\mathrm{OH}$ ligand hydrolyses the $\mathrm{Si}$ centre after creating a 5-coordinated specie and weakening the bridging bond (Fig. 2b). Moreover, the inclusion of hydrated cations to the quartz surface either enhances the physical access of $\mathrm{H}_{2} \mathrm{O}$ molecules to $\mathrm{Si}-\mathrm{O}$ bonds through reorientation of hydration waters to more productive sites, or transforms the mobility of connected $\mathrm{H}_{2} \mathrm{O}$, or increases the incidence of effective $\mathrm{Si}-\mathrm{O}$ hydrolysis reactions by enabling the discrete formation of $\mathrm{OH}$ ions at the interface, thereby increasing the nucleophilic nature of water (Zhang and Liu 2014). Although the development of only outer-sphere surface complexes by monovalent cations $\left(\mathrm{Na}^{+}\right.$and $\left.\mathrm{K}^{+}\right)$wields no effect on the hydrolysis of Si-O-Si linkages (Wallace et al. 2010), the inner-sphere surface complexes have been affirmed to be able to modify the activation energies considerably for such hydrolysis reactions (Dove 1999). On the other hand, secondary surface complexes of alkali silicates are adsorbed on quartz surface (Ali et al. 2017), accompanied by the cleaving of these sorbed cationic secondary phases, which accounts for quartz dissolution in alkali. However, the $\mathrm{Si}-\mathrm{O}-\mathrm{Si}$ hydrolysis-initiated surface complexes/ ligands are inconsistent phenomena in dissolution.

\section{Materials and methods}

\section{Computational method and model}

\section{Simulation of $\mathrm{NaOH}$ adsorption on quartz (001)}

The adsorption of $\mathrm{NaOH}$ was carried out using the Accelrys Material Studio software 6.0. Density functional theory (DFT) is a potent, quantum mechanics-based tool that predicts and calculates variations in internal energy of a crystal lattice with compression under varying conditions (Eschrig 2003). The DFT calculations were performed using the Cambridge Serial Total Energy Package (CASTEP) (Clark et al. 2005) contained in Material Studio software. The software implements the density functional theory (DFT) using periodic boundary conditions and a plane-wave basis set 

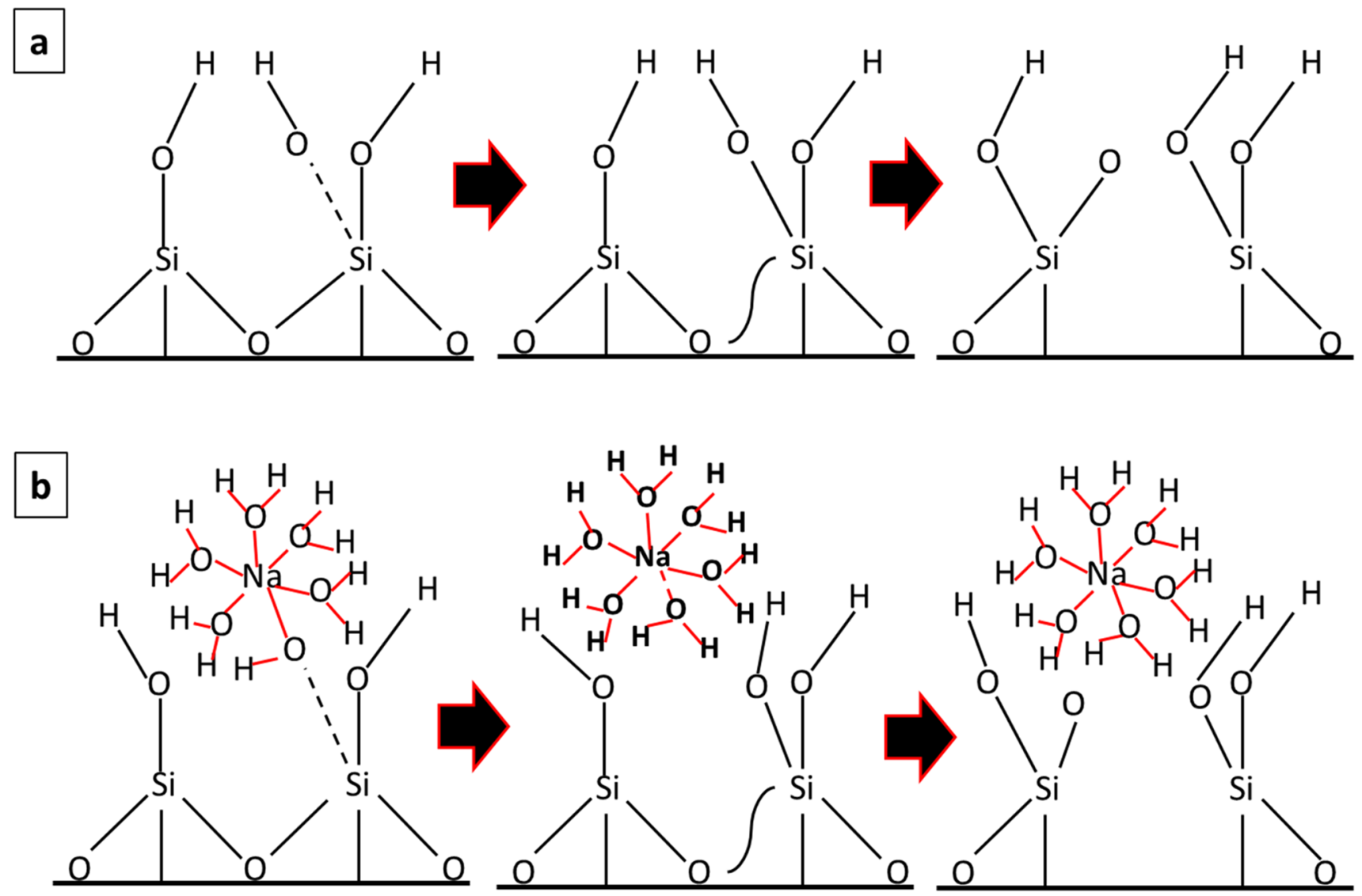

Fig. 2 Graphical representation of $\mathrm{NaOH}$ hydrolysis of quartz (Bickmore et al. 2008)

(Vanderbilt 1990). The DFT calculations utilized the Perdew-Burke-Ernzerhof function. The modelling involved several steps. The adsorbate $(\mathrm{NaOH})$ was drawn, cleaned, symbolically labelled and subsequently placed in a cubic cell for geometric optimization using the Forcite module before carrying out the adsorption. Then, unit cells of quartz $\left(\mathrm{SiO}_{2}\right)$ were introduced separately from material studio library and subsequently cleaved to (001) plane, as illustrated in Fig. 2. Thus, the quartz (001) surface (Fig. 3a) was cleaved (Fig. 3b) to form the basis for subsequent adsorption. The unit cell of cleaved quartz was enclosed in vacuum slabs with precise volumetric proportion, which was followed by Forcite geometry optimization. Afterwards, the optimized cleaved quartz was subjected to the Adsorption Locator module to determine the most stable active adsorption sites on the optimized cleaved quartz's surface.

\section{Surface models and surface energy calculation}

The silicon atom contained in $\mathrm{SiO}_{2}$ is sited at the tetrahedron centre of the structure with each silicon atom synchronized with four atoms of oxygen. For this study, the valence electron configurations of $\mathrm{SiO}_{2}$ include: $\mathrm{Si} 3 s^{2} 3 p^{2}$, O
$2 s^{2} 2 p^{4}$ and $\mathrm{H} 1 s^{1}$. The convergence tolerances for geometry optimization calculations include maximum displacement, maximum force, maximum energy change, maximum stress and SCF convergence tolerance of $0.002 \AA, 0.05 \mathrm{eV}^{-1}$, $2.0 \times 10^{-5} \mathrm{eV}$ atom $^{-1}, 0.1 \mathrm{GPa}$ and $2.0 \times 10^{-6} \mathrm{eV}$ atom $^{-1}$, respectively. Prior to adsorption, the $\mathrm{NaOH}$ was geometrically optimized. The quartz cell parameters obtained after minimization were $a=b=4.913 \AA, c=14.76 \AA$. The (001) cleaved quartz plane reveals three different exposed atoms. The cleaved surface results from the breaking of $\mathrm{Si}-\mathrm{O}$ bonds to produce highly reactive $\mathrm{Si}$ and $\mathrm{Si}-\mathrm{O}$ free radicals or ligands (Fig. 3b). It is commonly acknowledged that the stability of the cleaved surface increases with lower surface energy (Qiu et al. 2017). Compared to the Si termination and O-rich termination, cleaving on the O-middle termination requires less energy, signifying that it is potentially the most stable termination model of the quartz (001) surface. The single point energy type of calculation was employed.

The next stage involved $\mathrm{NaOH}$ adsorption on the cleaved quartz. Given the real mineral-water interface is hydrated, $\mathrm{H}_{2} \mathrm{O}$ molecules were first adsorbed on the cleaved quartz surface (Fig. 4a). A supercell surface was built to accommodate the isolated $\mathrm{H}_{2} \mathrm{O}$. Prior to the $\mathrm{NaOH}$ adsorption 
a

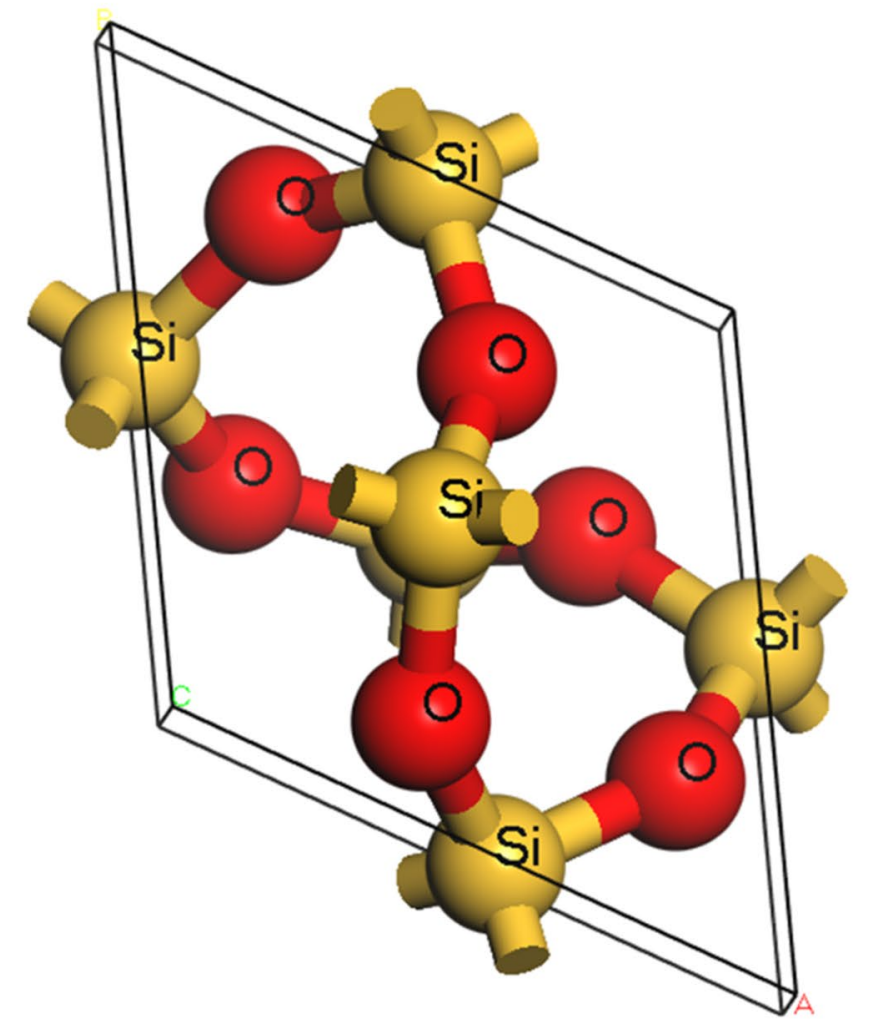

$10 !$ b

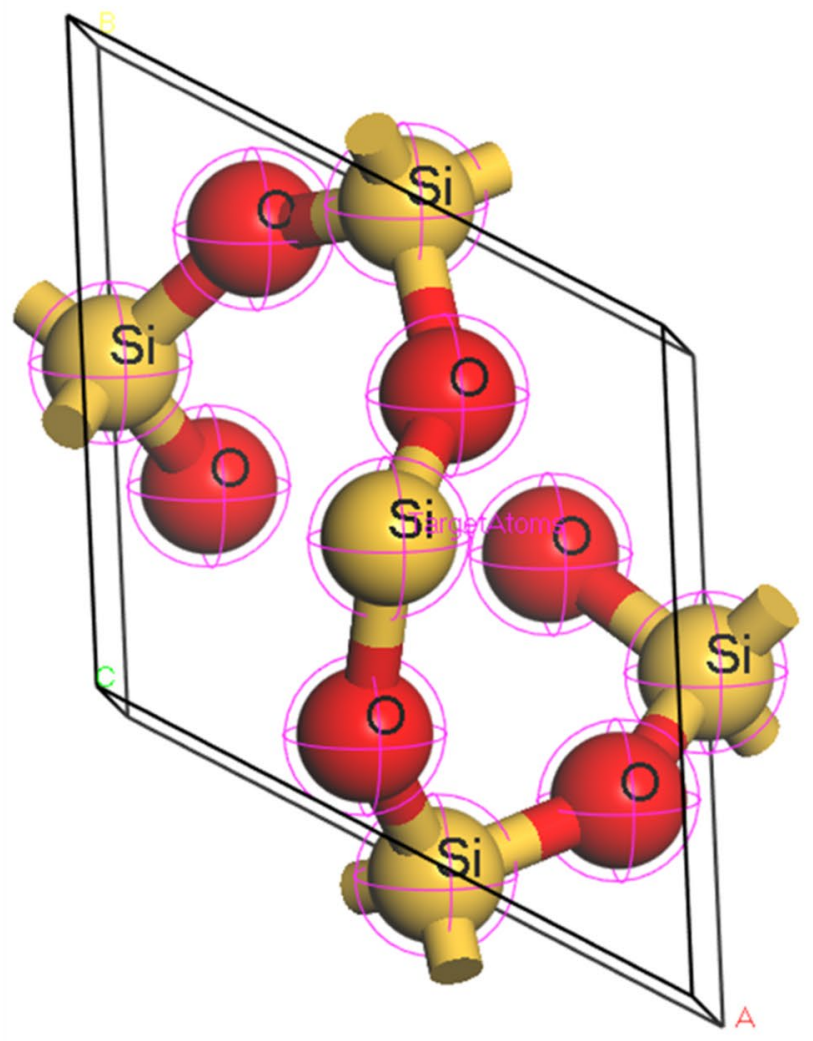

10 !

Fig. 3 The cell model of (a) ball and stick quartz model; (b) quartz surface cleaved at (001)

a

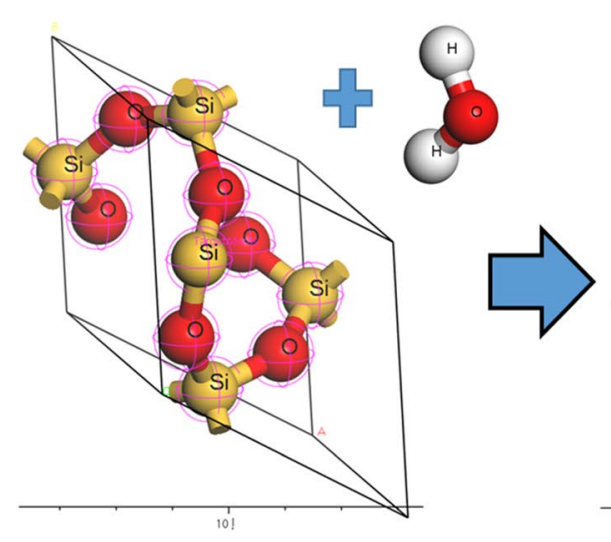

b

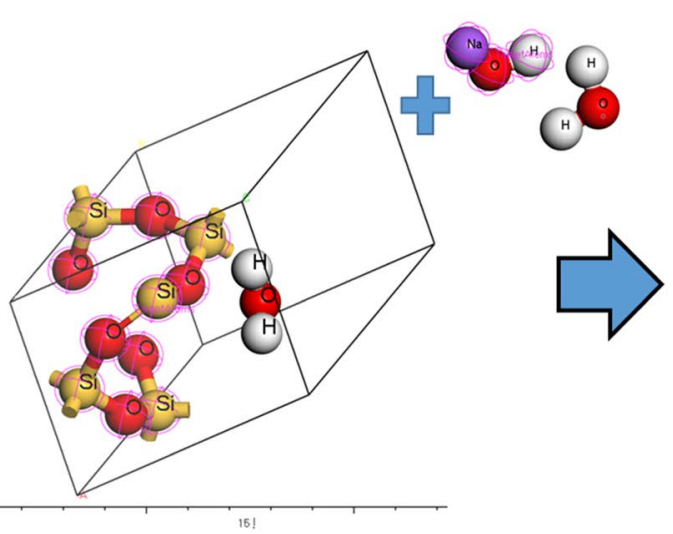

C

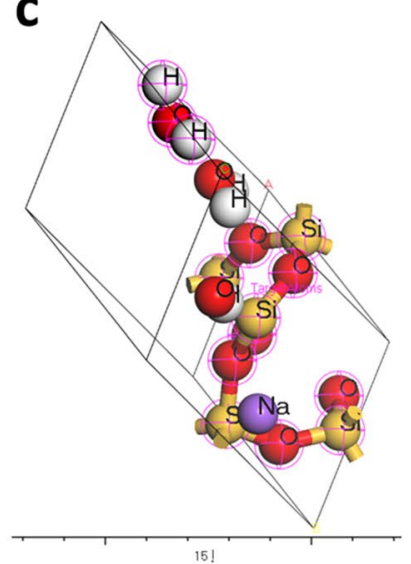

Fig. 4 a Cleaved quartz (001) surface structure and $\mathrm{H}_{2} \mathrm{O}$ molecule, b molecular adsorption model for $\mathrm{H}_{2} \mathrm{O}$ molecule adsorbed on quartz, $\mathrm{NaOH} \cdot \mathrm{H}_{2} \mathrm{O}$, c molecular adsorption model of $\mathrm{NaOH} . \mathrm{H}_{2} \mathrm{O}$ (adsorbate) over hydrated quartz 
configuration, the amorphous cell of the hydrated quartz was transformed into a supercell and a vacuum slab was created afterwards. As illustrated in Fig. 4b, c, $\mathrm{H}_{2} \mathrm{O}$ was adsorbed on $\mathrm{NaOH}$. The adsorbate $\left(\mathrm{NaOH} \cdot \mathrm{H}_{2} \mathrm{O}\right)$ was then imported into the vacuum slab of hydrated quartz, and the target atoms were marked. The adsorption module was then run. This procedure was repeated, but this time atomic layer number of the quartz along with the loadings of $\mathrm{H}_{2} \mathrm{O}$ and $\mathrm{NaOH}$ was increased to generate a five-layered structure. The resulting molecular models are presented in Fig. 5. This was done to determine possible variation in adsorption energy with number atomic layers.

Afterwards, DFT was also applied to simulate the adsorption energy between the molecules of the $\mathrm{NaOH}$ adsorbate and sandstone reservoir rock surfaces. Sandstone with porosity of $24 \%$ and composition of quartz, feldspar and kaolinite was used. The procedural steps for constructing reservoir sandstone in Material Studio are presented in Fig. 6. The sandstone components (quartz, feldspar and kaolinite) were separately constructed and then geometrically optimized (step 1). In step 2, an amorphous cell was built. The sandstone components were subsequently imported into the amorphous cell. For step 3, oil $\left(\mathrm{C}_{8} \mathrm{H}_{18}\right)$ and brine $\left(\mathrm{H}_{2} \mathrm{O}+\mathrm{NaCl}\right)$ were incorporated into the cell to fully replicate the reservoir environment. The adsorption energies of the $\mathrm{NaOH}$ on the sandstone in the presence of brine and oil were measured using the adsorption configuration locator.

\section{Experimental quartz dissolution}

Laboratory experiments of quartz dissolution in $\mathrm{NaOH}$ involved the use of Teflon reaction vessels sheathed in ceramic bombs containing a few quartz grains $(\leq 2 \mathrm{~mm})$ and
$50 \mathrm{ml}$ of the alkali solution $(\mathrm{NaOH})$. The bombs were then placed in a water bath shaker set at $100^{\circ} \mathrm{C}$ for a duration of $20 \mathrm{~h}$ and subsequently cooled in cold running water. Afterwards, the quartz grains were removed and placed under a stream of distilled water for approximately a quarter of an hour to help dispel the adsorbed artefacts and products of the reaction. Some of the quartz grains were directly studied after drying to provide a realistic view of alkali $(\mathrm{NaOH})$-dissolved quartz. The surface microtextural features and sorbed phases of the dissolved quartz substrate were studied with the use of field emission scanning electron microscopy (Carl Zeiss Supra 55VP FESEM; operated at 5-20 kV).

\section{Results and discussion}

\section{Adsorption locator calculations and CASTEP simulation}

CASTEP simulation was used to elucidate the action of $\mathrm{NaOH}$ molecules adsorbed on the optimized $\mathrm{SiO}_{2}$ surfaces, by acquiring data on orbital overlapping, electron density, band structures, band gap, orbital and spin density of states (DOS). From the DFT calculations, the O-middle termination exhibited the lowest surface energy at $1.969 \mathrm{~J} \mathrm{~m}^{-2}$ compared to the others (surface energies of $2.896 \mathrm{~J} \mathrm{~m}^{-2}$ and $2.892 \mathrm{~J} \mathrm{~m}^{-2}$ for Si and O-rich terminations, respectively.

\section{Adsorption of an isolated $\mathrm{NaOH}$ on quartz (001) surface}

$\mathrm{NaOH}$ adsorbed on the cleaved quartz (001) surface was analysed according to the $\mathrm{O}$-middle termination because it is the most stable quartz (001) termination. A supercell
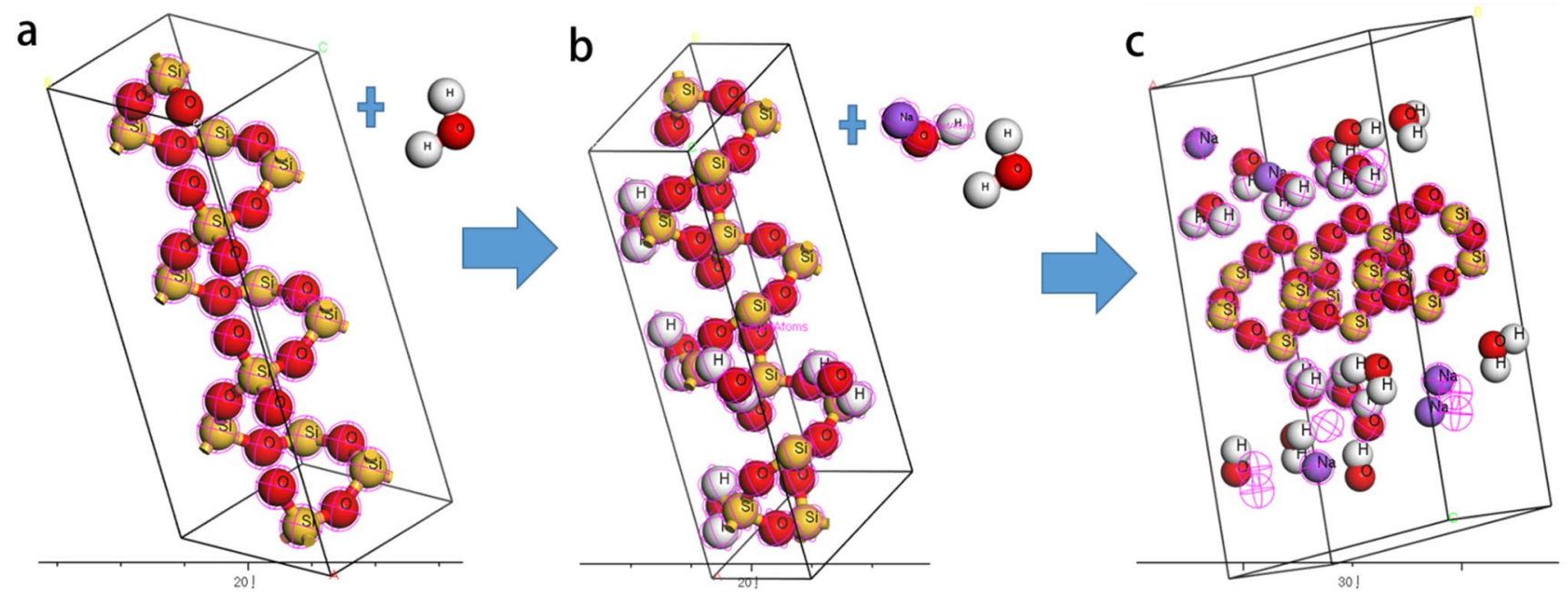

Fig. 5 a Molecular adsorption model for $\mathrm{H}_{2} \mathrm{O}$ molecule, b molecular adsorption model for hydrated quartz, c molecular adsorption model of $\mathrm{NaOH}$ ionized in $\mathrm{H}_{2} \mathrm{O}$ (adsorbate) over targeted hydrated quartz 

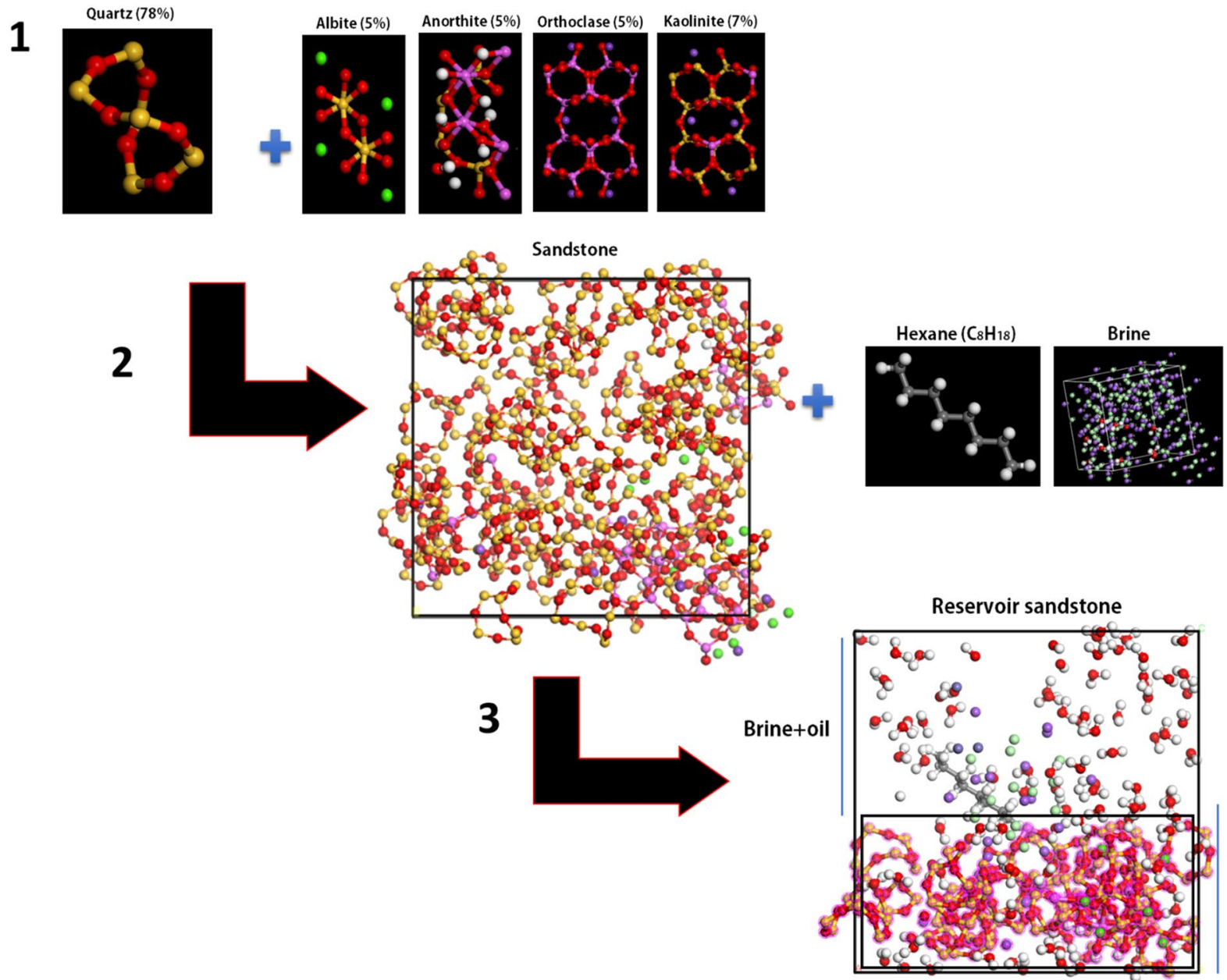

Sandstone

Fig. 6 Procedural steps for constructing reservoir sandstone in Material Studio

surface was constructed to incorporate the discrete adsorption of $\mathrm{NaOH}$ on quartz surfaces. The optimized geometry of $\mathrm{NaOH}$ adsorbed on quartz is depicted in Fig. 7, and their adsorption energies are presented in Table 1. The adsorption characteristics of $\mathrm{NaOH}$ on the hydrated quartz were derived by determining the preferred adsorption geometries and their equivalent adsorption energies calculated from the equation below:

$E_{\text {ads }}=E_{\text {surface }+\mathrm{NaOH}}-\left(E_{\text {surf }}+E_{\mathrm{NaOH}}\right)$

where $E_{\text {surface+NaOH}}$ is the total energy of the adsorbate-substrate system, $E_{\text {surf }}$ is the energy of the adsorbent (hydrated quartz) surface, and $E_{\mathrm{NaOH}}$ is the energy of the adsorbate $\left(\mathrm{NaOH} \cdot \mathrm{H}_{2} \mathrm{O}\right)$. The adsorption energy values are outlined in Table 1 . The calculated adsorption energy values were $-1.44 \mathrm{kcal} / \mathrm{mol}$ and $-5.90 \mathrm{kcal} / \mathrm{mol}$ for a single atom layer and five-layered atomic structure, respectively. A negative value for the absorption energy means that the corresponding adsorbed state is thermodynamically more stable than the unbound state. Based on the adsorption energies obtained in the DFT calculations, molecular adsorption (intramolecular energy) is favourable for isolated $\mathrm{NaOH}$ on the O-middle termination of a quartz (001) surface. DFT calculation shows intramolecular energy is the dominant adsorption energy, followed by weak van der Waals energy (Fig. 8). Thus, the $\mathrm{NaOH}$ adsorption transforms the structure, electronic properties of the quartz surface using both molecular and van der Waals energies. Accordingly, $\mathrm{NaOH}$ molecule adsorption is dependent on both the structure and electronic properties of the quartz.

\section{Band structure}

The locus of the Fermi level $\left(E_{\mathrm{F}}\right)$ is $0 \mathrm{eV}$. The region close to the Fermi level is crucial for different physiochemical properties that include conductor type, surface reaction activity and electrochemical potential of minerals (Escamilla-Roa et al. 2017). Figure 9 shows the reaction mechanism with and without the $\mathrm{NaOH}$ adsorption in terms of band structure.

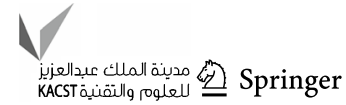



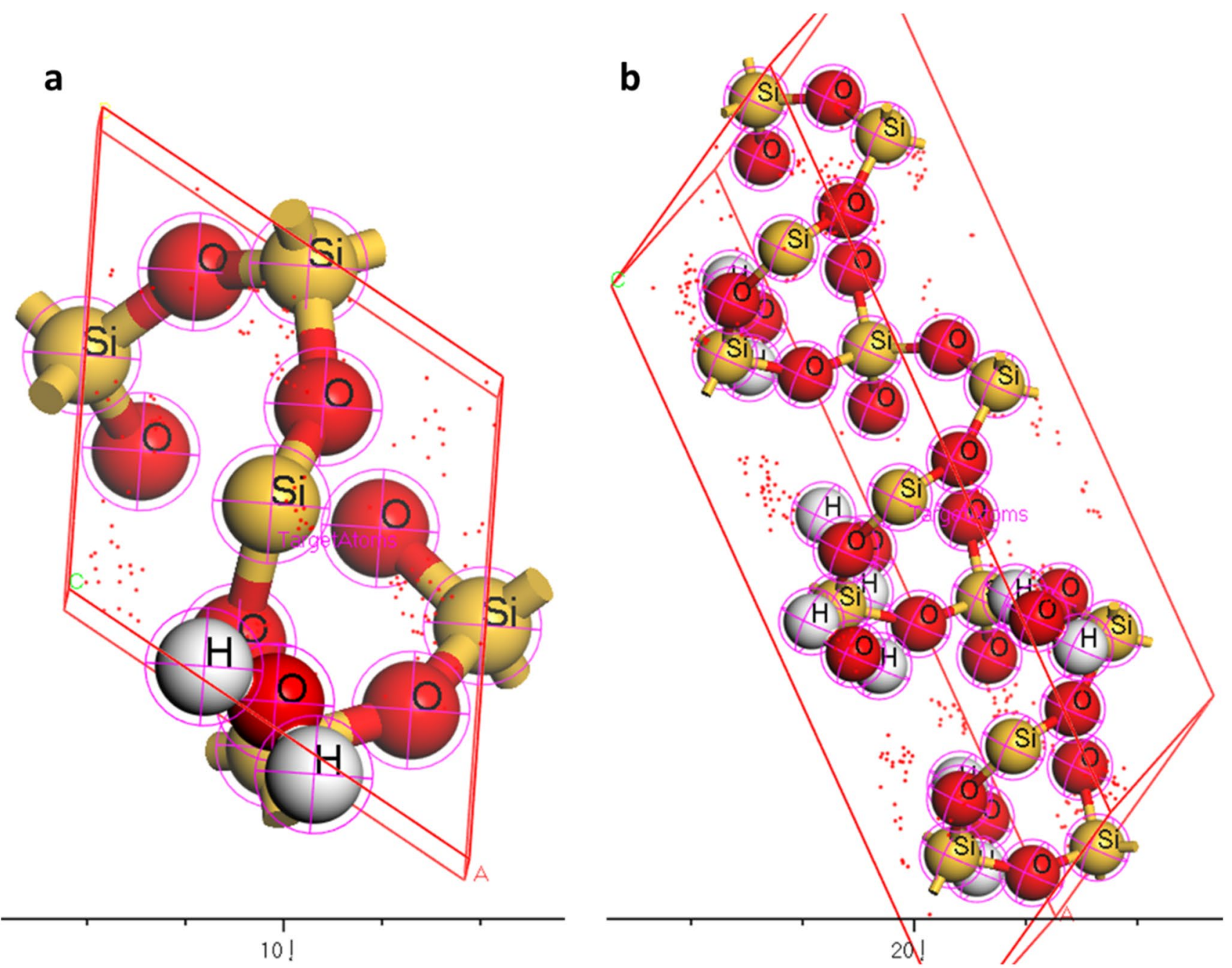

Fig. 7 Optimized geometry of $\mathrm{NaOH}$ adsorbed on quartz, with the red dots denoting the $\mathrm{NaOH}$ adsorbates

Table 1 Adsorption energy for the different simulated structures

\begin{tabular}{lllc}
\hline Structures & $\begin{array}{l}\text { Total energy }(\mathrm{kcal} / \\
\mathrm{mol})\end{array}$ & $\begin{array}{l}\text { Adsorption energy } \\
(\mathrm{kcal} / \mathrm{mol})\end{array}$ & $\begin{array}{c}\text { Rigid adsorption } \\
\text { energy }(\mathrm{kcal} / \mathrm{mol})\end{array}$ \\
\hline Single hydrated quartz atom $\left(E_{\text {surf }}\right)$ & -2.95547 & -2.95549 & -2.95555 \\
Five-layered hydrated quartz $\left(E_{\text {surf }}\right)$ & -14.5534 & -14.5535 & -14.5537 \\
$\begin{array}{l}\text { Single } \mathrm{NaOH} \text { adsorbed on a hydrated } \\
\text { quartz atom }\left(E_{\text {surf }+\mathrm{NaOH}}\right)\end{array}$ & -4.80874 & -13.9668 & -4.47528 \\
$\begin{array}{l}\text { Five-layered } \mathrm{NaOH} \text { adsorbed on hydrated } \\
\text { quartz }\left(\mathrm{E}_{\text {surf }+\mathrm{NaOH}}\right)\end{array}$ & -22.5098 & -68.3 & -20.5787 \\
$\mathrm{NaOH} \cdot \mathrm{H}_{2} \mathrm{O}$ & -0.4115 & -0.41152 & -0.4115 \\
\hline
\end{tabular}

The blue lines indicate spin lines. Figure 9a shows band structure of cleaved $\mathrm{SiO}_{2}$ (001) surface, whereas Fig. 9b shows the band structure for $\mathrm{NaOH}$ adsorbed on quartz (001) surface. The cleaved $\mathrm{SiO}_{2}(001)$ surface constitutes a higher band gap of $0.157 \mathrm{eV}$ compared to $0.138 \mathrm{eV}$ for $\mathrm{NaOH}$ adsorbed on quartz (001) surface. In addition, the energy range of $\mathrm{NaOH}$ adsorbed on quartz is wider $(-50$ to $10 \mathrm{eV})$ compared to (001) quartz ( -20 to $11 \mathrm{eV}$ ). Top of the valence band and bottom of the conductive bands are occupied by $\mathrm{Si}$ $p$ states. The narrow band at the bottom of Fig. 8 indicates oxygen's $s$ state combined with $\mathrm{Si} p$ state. The adsorption of $\mathrm{NaOH}$ molecules on the $\mathrm{SiO}_{2}$ (001) surface tightens the band gap. The wave functions of the electrons bound to the $\mathrm{NaOH}$ atoms create an overlap that forces the energies to 
Fig. 8 The different kinds of energy involved in the adsorption $\mathrm{NaOH}$ on cleaved quartz

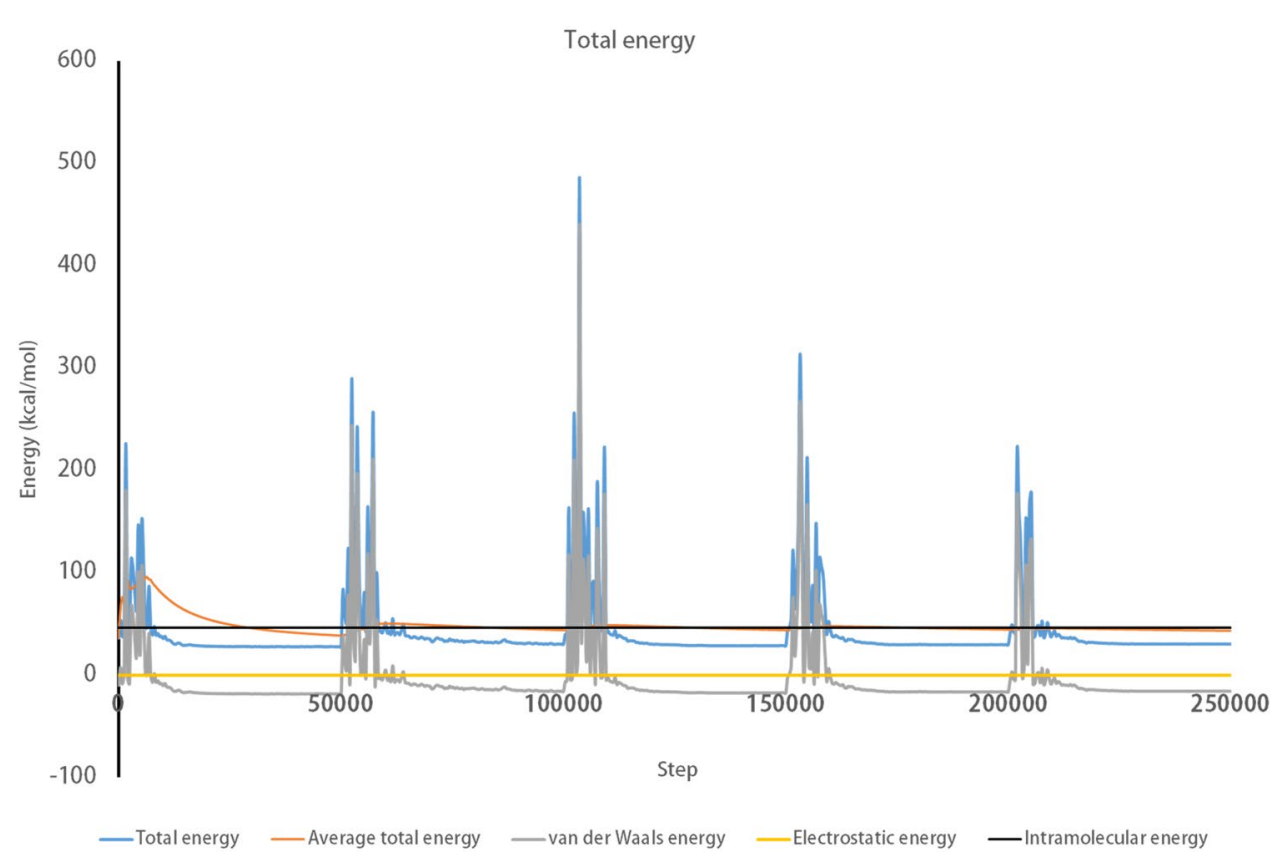

\section{a}

\section{Energy (eV)}

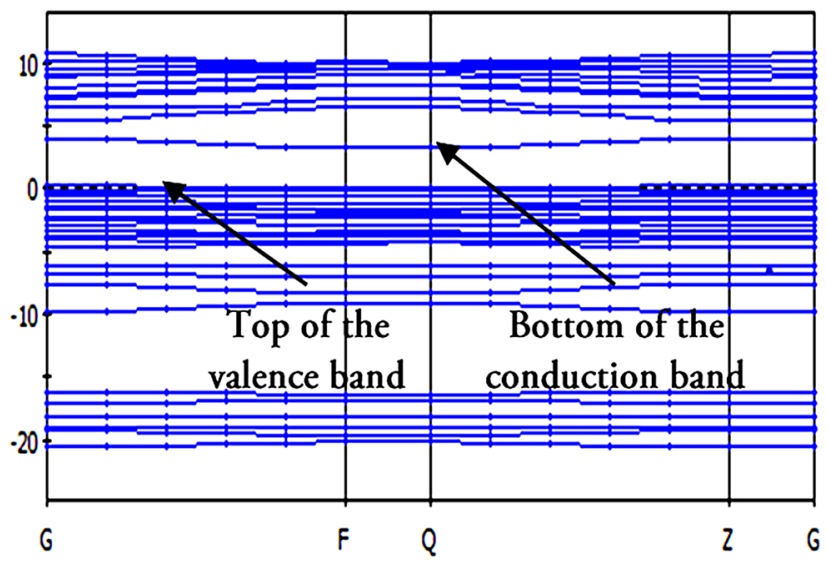

b

Energy (eV)

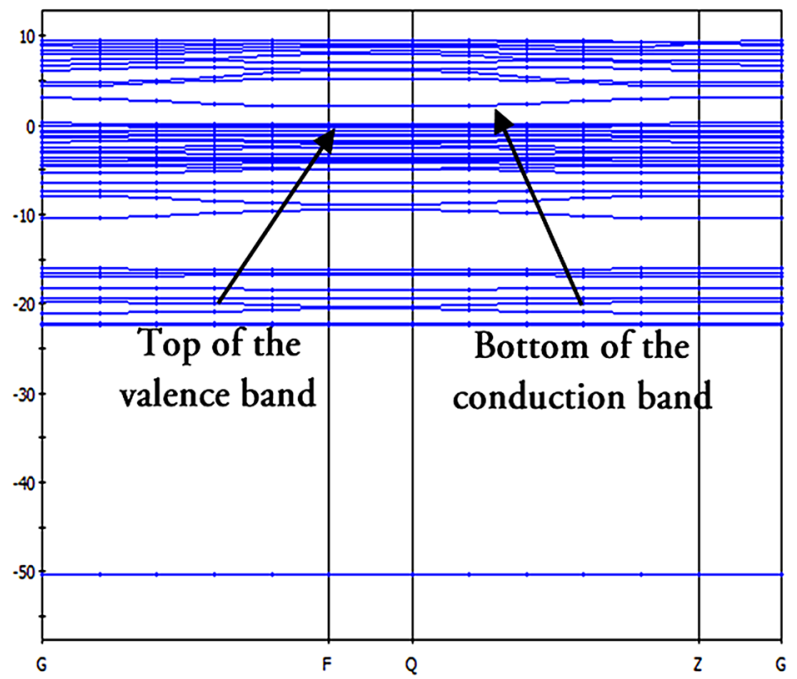

Fig. 9 Band structure of a cleaved $\mathrm{SiO}_{2}$ (001) surface, $\mathbf{b} \mathrm{NaOH}$ adsorbed on quartz (001) surface

form an energy band rather than a discrete level. However, after $\mathrm{NaOH}$ absorption, occupancy of energy levels remains almost same because the 'doping' density of $\mathrm{NaOH}$ is not high enough to generate a band. Hydrogen's s state can be clearly seen at the lowest energy level, as shown in Fig. 9b.

\section{Density of states (DOS)}

Density of states (DOS) is a vital parameter for defining the states of motion of electrons in solid state physics, defining how many energy states exist at a given energy. The DOS in the conduction band depends on available states for occupation, while the valence band depends on the probability than an electron occupies an available quantum state, taking 


\section{a CASTEP Partial Density of States}

\section{Energy (eV)}
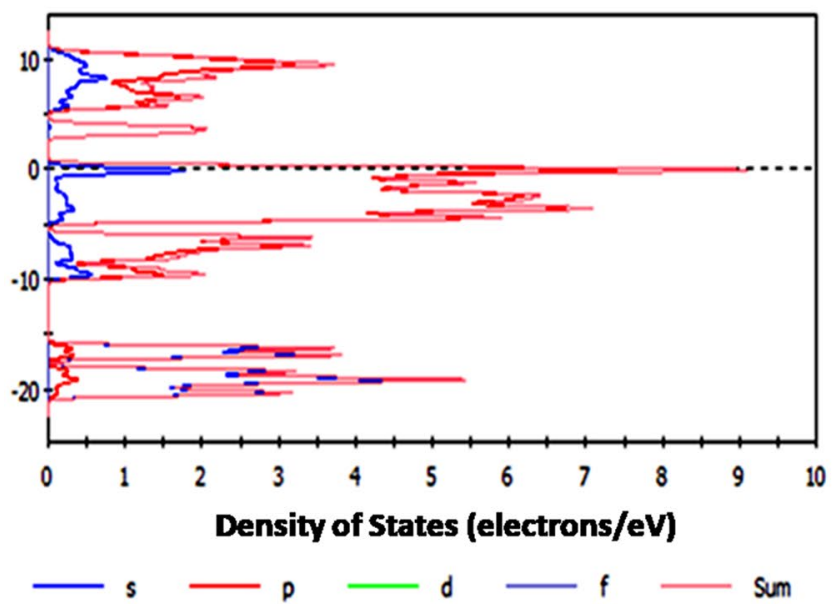

\section{b CASTEP Partial Density of States}

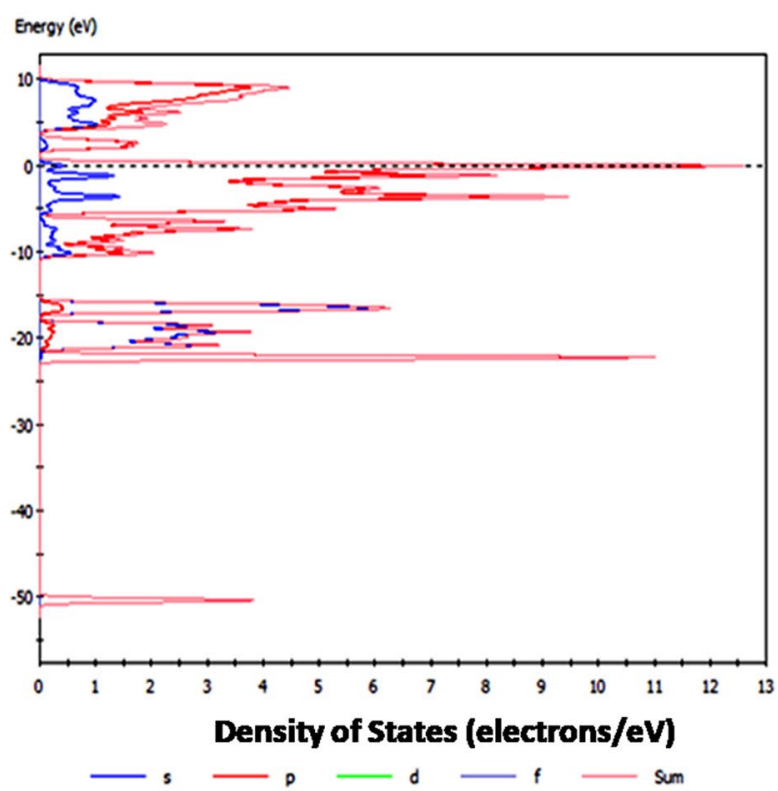

Fig. 10 Projected density of states (PDOS) of a cleaved quartz (001) surface, $\mathbf{b} \mathrm{NaOH}$ adsorbed on quartz (001) surface

into account Pauli's exclusion principal. Figure 10 presents the partial orbital of states of sub-orbitals ( $s, p, d$ and sum) of the cleaved quartz (001) surface and $\mathrm{NaOH}$ adsorbed on quartz (001) surface. From Fig. 10, it is evident that the existing energy orbital states below Fermi level are ascribed to $s$ and $p$ orbitals. It can be deduced that the activity of electrons at $p$ states is significantly larger compared to the $s$ states. The $p$ states occupy the top of the valence band and bottom of the conductance band, particularly in the region of the Fermi (EF) level. In addition, occupied energy levels for both $\mathrm{NaOH}$ absorbed on quartz surface and the cleaved $\mathrm{SiO}_{2}$ are almost same. However, total orbital, as well as $\mathrm{p}$ orbital, DOS for $\mathrm{NaOH}$ adsorbed on quartz (001) surface is higher than cleaved $\mathrm{SiO}_{2}(001)$ surface below and above Fermi level. Therefore, considering details at the vicinity of Fermi level, activity of $\mathrm{NaOH}$ adsorbed on quartz (001) surface is greater than that of cleaved $\mathrm{SiO}_{2}(001)$.

\section{Simulated $\mathrm{NaOH}$ interaction with reservoir sandstones}

The adsorption module was then run to create a combined adsorbent-adsorbate structure (Fig. 11). The Adsorption Locator module performs a simulation of the reservoir environment, which comprises quartz substrates loaded with brine, oil, feldspars and clays of fixed composition. The adsorption energies of the different reservoir components were measured using the adsorption configuration locator. The adsorption energy calculation combines the bonding (stretching, bending, torsion energy and the diagonal and off-diagonal cross-coupling terms) and nonbonding terms. Similar to the cleaved single quartz, the dominant energies involved in $\mathrm{NaOH}$ interaction with the reservoir sandstones are intramolecular. However, an energy difference was observed. The intramolecular energy for adsorption increased drastically to $270 \mathrm{kcal} / \mathrm{mol}$. The average total energy also increased significantly from 20 to $210 \mathrm{kcal} / \mathrm{mol}$ (Fig. 12). This significantly higher adsorption energy for $\mathrm{NaOH}$ interactions with reservoir sandstone compared to the solitary crystal grains can be attributed to the different components incorporated into the system (Aufort et al. 2015; Pertsev and Salje 2000; Zubko et al. 2013).

\section{Stress autocorrelation function (SACF) for shear viscosity behaviour}

Stress autocorrelation function (SACF) is pressure function that denotes shearing force, and thus used to explain the stresses the $\mathrm{NaOH}$-dissolved quartz is subjected to due to the diffusion of $\mathrm{Na}$ and $\mathrm{OH}$ molecules, resulting in intermolecular kinetics. The shearing force refers to molecular stresses caused by attraction and repulsion of $\mathrm{Na}, \mathrm{OH}$ and $\mathrm{Si}$ and $\mathrm{O}$ molecules. The SACF values are used to infer viscosity of reservoir fluids. However, as the SACF reaches stability, it begins to congregate to attain a monotonic/harmonic level, which indicates that the analysed viscosity is acceptable. 


\section{Reservoir sandstone}

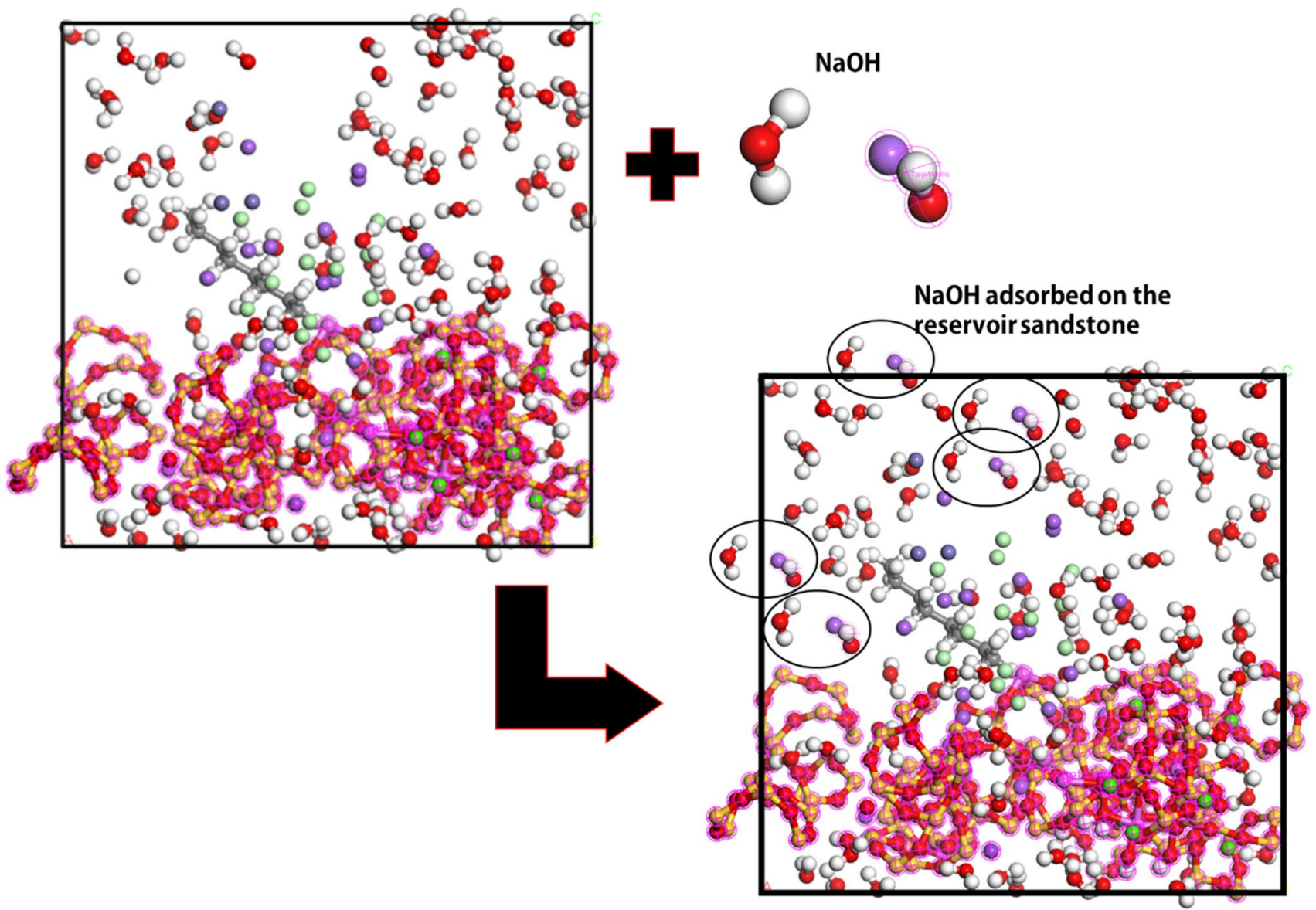

Fig. 11 Geometry of $\mathrm{NaOH}$ adsorption on reservoir sandstone

Fig. 12 The different kinds of energy involved in the adsorption of $\mathrm{NaOH}$ on reservoir sandstone
Total Energy

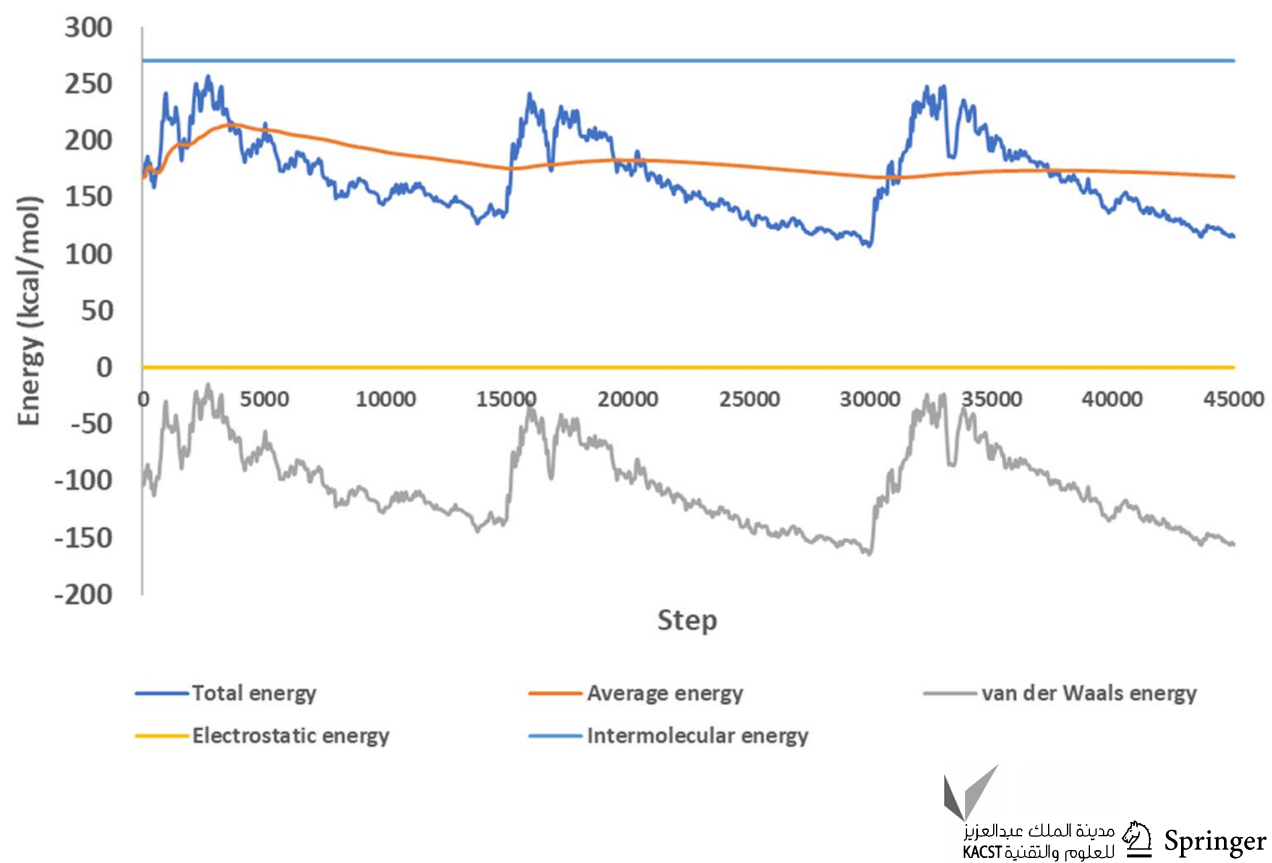




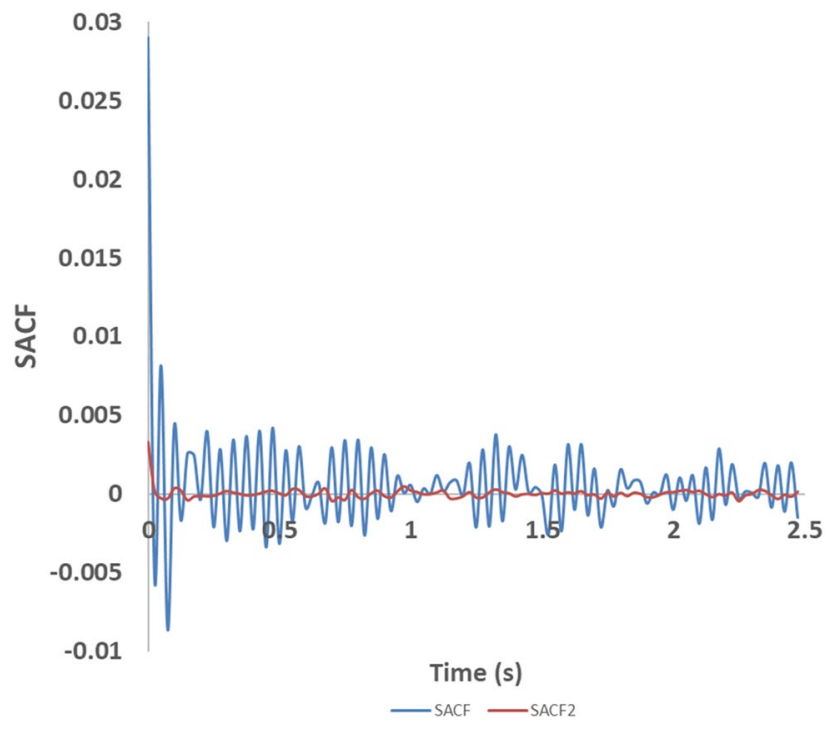

Fig. 13 Plot of SACF values for pure quartz (SACF) and $\mathrm{NaOH}$ adsorbed on quartz (SACF2)

The SACF was performed in the Materials Studio simulation software, at reservoir temperature of $120^{\circ} \mathrm{C}$ and pressure of $70 \mathrm{MPa}$. The SACF plot for reservoir sandstone and with the addition of $\mathrm{NaOH}$ is shown in Fig. 13. For the ideal $\mathrm{SiO}_{2}$ system (SACF2), the SACF remains relatively stable and undulating at zero (0) with time. With the incorporation of $\mathrm{NaOH}$ (SACF), the SACF slightly increases and resonates between 0 and 0.02 , indicating improved stress in the system. This implies stress is imparted on the viscosity of fluids in the reservoir with the addition of $\mathrm{NaOH}$. The imparted stress reduces viscosity, thereby improving fluid mobility in the reservoir.

\section{Surface microtextural characterization of dissolved quartz}

The surface of the $\mathrm{NaOH}$-dissolved quartz was characterized using scanning electron microscopy (SEM). The morphological dissolution features include surface smoothening, etch pits, striations and chatter mark/curved trails. The SEM images of the in situ unwashed samples depict fibrous strands of sodium silicate, which are derived from the reaction of dissolved silica with sodium ions from the hydroxide, enmeshed into the quartz grains (Fig. 14a). These precipitated laths expand the crystal lattice of the quartz. The laths of sodium silicates are also shown as fibrous bundles that are stacked in between adjoining grains (Fig. 14b). This phase of sorbed silicates generally shows another perspective of etch pit development on quartz surface, where a new void is created through the 'cleaving off' of the sodium silicates sorbed into the quartz surface, instead of the traditional concept of dissolution of a pre-existent crystal void.
In the case of washed quartz grains, continuous elongated striations and curved trails rather than distinct etch marks can be observed on the quartz surface (Fig. 14c). The microstructures merge to such an extent that their size cannot be determined precisely. Figure $14 d$ shows etch pits resulting from intense quartz dissolution. The walls of the etch pits will gradually advance into unreactive negative crystal faceted forms. The quartz textural disparities can be ascribed to density variations of pre-existing steps in the original crystal surface or dislocation points (Yanina et al. 2006) as well as the differential sizes of sodium silicates. The precipitation of sorbed phases suggests that the dissolution reaction needs to be incongruent (the forward reaction of dissolution should be faster than the backward reaction, i.e. disequilibria) to ensure the development of etch pits, which will serve as micro- and nanopores (Pollard et al. 1989). This phase or layer of adsorbed silicate (Fig. 14a, b) represents an intermediate species between the quartz solid and dissolved silica. The quartz surface textural study indicates that dissolution of crystalline (granite) and clastic rocks (sandstone) is critical to the development of voids, which will improve permeability by providing channels and routes for the passage of hydrothermal and reservoir fluids.

\section{Discussion}

The selectivity of $\mathrm{NaOH}$ absorption on quartz surface can be inferred. The $\mathrm{NaOH}$ adsorbate is dissociated into $\mathrm{Na}$ and $\mathrm{OH}$ (Fig. 15a), after being ionized in solution. From the dissociated adsorption model, Na prefers to adsorb on the most stable quartz (001) termination (O-middle termination) via $\mathrm{Na}-\mathrm{O}$ bond at $3.828 \AA$, while the $\mathrm{OH}$ selects the Si termination via $\mathrm{Si}-\mathrm{OH}$ bond at $4.605 \AA$ (Fig. 15b). This implies that the surface of quartz is hydroxylated after adsorption of the $\mathrm{H}_{2} \mathrm{O}$ molecule. The bond lengths of the newly formed bonds are highlighted in green (Fig. 15b).

Previous studies reported that the O-middle termination is the most stable model of quartz (001) surface, with $\mathrm{H}_{2} \mathrm{O}$ adsorption on quartz achieved through van der Waals force and weak hydrogen bond (Wang et al. 2018). Although this current study established the contribution of van der Waals force, intramolecular energy was found to be the dominant energy controlling the adsorption process. Most importantly, an energy difference was observed between the adsorption of $\mathrm{NaOH}$ on single quartz crystal (as performed in earlier studies) and that of quartz in a polymineralic scenario (reservoir sandstone). The intramolecular energy for adsorption increased drastically to $270 \mathrm{kcal} / \mathrm{mol}$. The average total energy also increased significantly from 20 to $210 \mathrm{kcal} / \mathrm{mol}$. Thus, contrary to the homogenous deformation of a solitary crystal, dissolution reactions in granular quartz are affected 


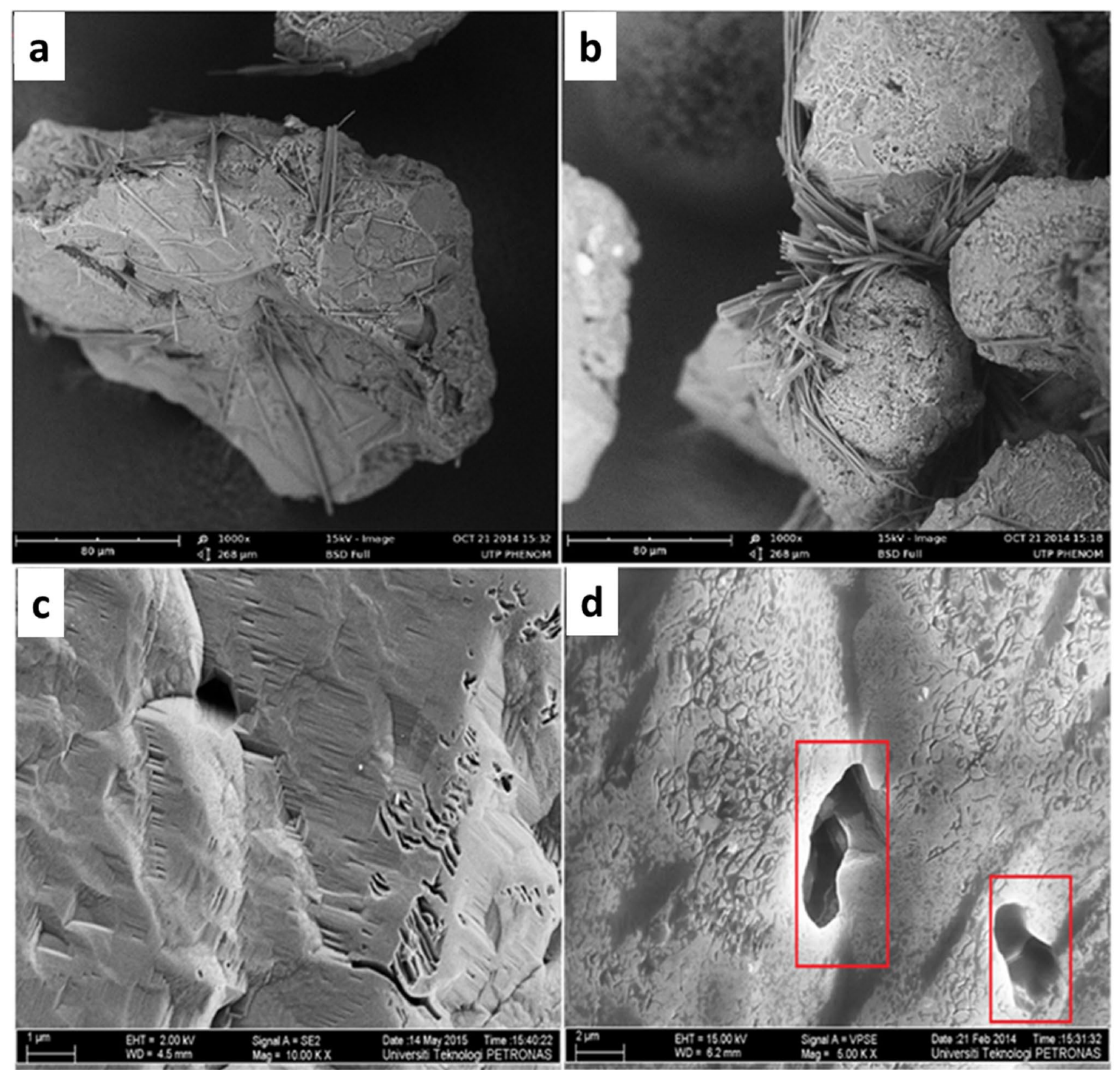

Fig. 14 FESEM of quartz surface showing: a needle-like shaped laths of sodium silicate sorbed on the quartz surface, $\mathbf{b}$ laths of sodium silicates are also shown bundled between quartz, $\mathbf{c}$ striations and curved trails, $\mathbf{d}$ etch pits

by anisotropic deformations of contiguous grains (Aufort et al. 2015). It has been posited that such inhomogeneous deformations in polymineralic sandstone result in phase variations (Pertsev and Salje 2000), where the stepwise transition would be levelled, and the transition temperature would rise. Porosity of sandstone may, in principle, increase the energy distribution. It is likely that the combination of polarization from $\mathrm{NaOH}$ adsorption with strain gradient derived from motion of adjacent quartz grains can disrupt the local symmetry (Zubko et al. 2013). High porosity subsequently infers larger surface vibrations and thus higher energy distributions. The quartz grains in the sandstone are arbitrarily positioned, so the bulk material is subject to isotropic expansion that is averagely consistent with that of the singular grain.

Zhang and Liu (2014) and Ali et al. (2017) reported that surface complexes and morphological features of dissolved quartz are dependent on $\mathrm{pH}$ and electrolyte conditions, while the computational study by Nangia and Garrison (2008) noted that quartz dissolution is controlled by the distribution of protonated, deprotonated or neutral species. The adsorption of alkali metal ions was reported to weaken the 


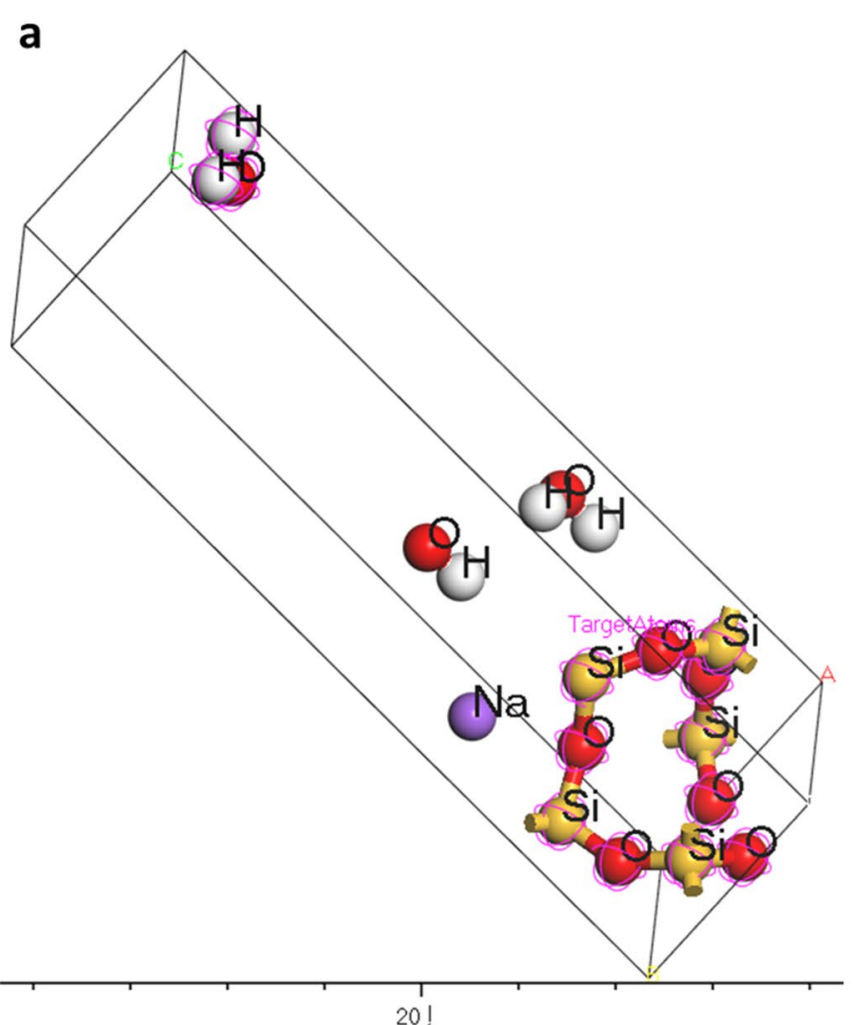

b

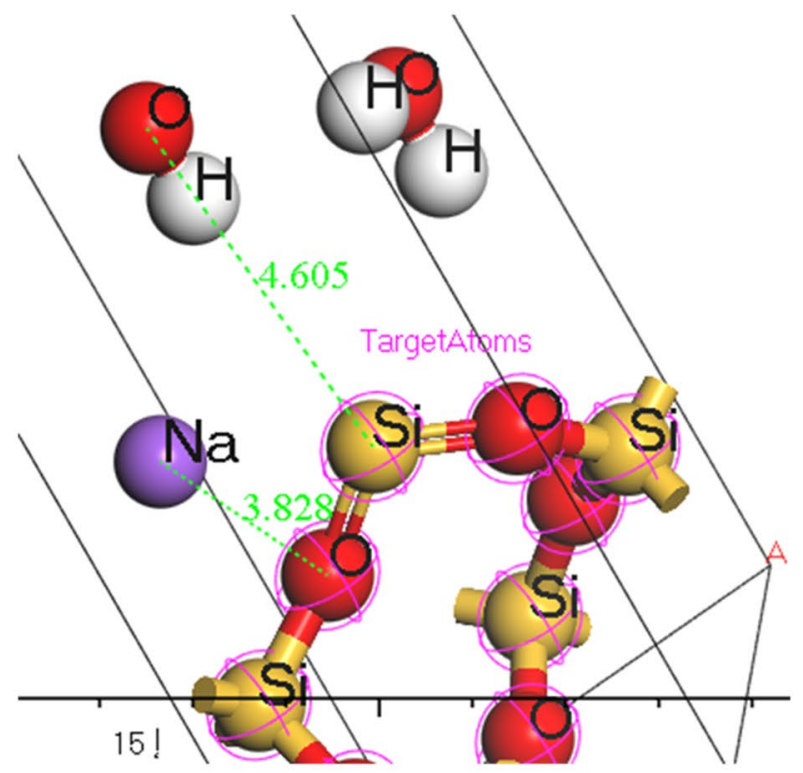

Fig. 15 a Dissociative adsorption model of $\mathrm{NaOH}$ on quartz, b zoomed in view of the adsorption structure

$\mathrm{Si}-\mathrm{O}$ bond by reducing the reaction barrier heights thereby increasing hydrolysis (Ali et al. 2017). Rimstidt (2015) posited the integration of existing surface complexation, surface charge, terrace-ledge-kink and Lewis acid-base models into a reliable model of quartz dissolution reaction. This study takes a different approach to elucidating quartz dissolution. Based on the quartz dissolution review (Nangia et al. 2007; Bickmore et al. 2008; Pelmenschikov et al. 2000; Xiao and Lasaga 1996; Wallace et al. 2010), microtextural analysis of dissolved quartz and DFT simulation data, the mechanism of quartz dissolution is being reassessed to reflect realistic geological scenarios. Figure 16 illustrates the proposed model. First, the siloxane bonds $(\mathrm{Si}-\mathrm{O}-\mathrm{Si})$ in quartz form hydrolysed silica species $(\mathrm{Si}-\mathrm{OH})$ when reacting with water at neutral pH [Eq. (3)]. Subsequently, continuous reaction with water causes the protonation of $\mathrm{Si}-\mathrm{OH}$ to form $\mathrm{SiOH}_{2}$ ligands on the quartz surface [Eq. (4)]. At this point, the adsorption energies from intramolecular forces facilitate the bonding of the $\mathrm{H}^{+}$ions with the silica species. As $\mathrm{pH}$ increases with the immersion in alkali solution $(\mathrm{NaOH})$, the hydrolysed silica species begins to deprotonate due to interactions with $\mathrm{OH}^{-}$ions [Eq. (5)]. This deprotonation mechanism is enabled by desorption energies derived from endothermic reactions between the monovalent cations, hydroxyl ions and quartz surface ligands, as indicated by the high intermolecular energy of $250 \mathrm{kcal} / \mathrm{mol}$ and increase in shearing force and perturbation (i.e. increase in SACF). The deprotonation reaction reduces $\mathrm{SiOH}_{2}$ to $\mathrm{SiO}^{-}$[Eq. (6)]. The desorbed $\mathrm{H}$ ions create vacancies in the initial siloxane and $\mathrm{SiOH}$ bonds, which are represented as the defects (etch pits) observed on the quartz surface. However, the band structure shows the occupancy of energy levels remains almost same after $\mathrm{NaOH}$ absorption, which can be attributed to the stable $\mathrm{Si}-\mathrm{O}$ quartz bonds. Nonetheless, the slight drop in band gap from 0.157 to $0.138 \mathrm{eV}$ and expanded energy range from $(-20$ to $11 \mathrm{eV})$ to $(-50$ to $10 \mathrm{eV})$ are suggestive of increasing interactions, density variations, improved conductivity and molecular changes of surface ligands on the quartz. Moreover, the anisotropic deformations derived in polymineralic scenario (sandstone) increase the energy in the system, which points to possible faster quartz dissolution. Thus, despite the strong covalent bonds of quartz, the formation of surface ligands due to adsorption of cations and hydroxyls on quartz and subsequent cleaving of these silica species allow for quartz dissolution. The dominant intramolecular energy indicates chemical bond formation of the hydroxide adsorbate with the oxide substrate, while the van der Waals energy stabilizes the adsorbed $\mathrm{NaOH}$ molecules (Dzade et al. 2014). 


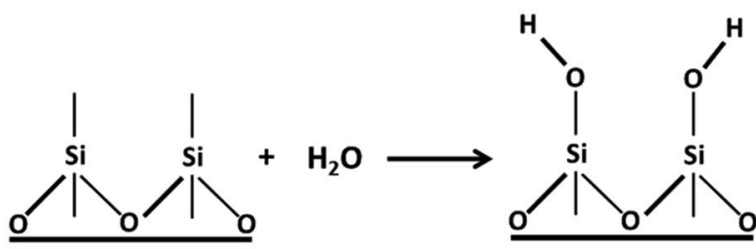

$\equiv \mathrm{Si}-\mathrm{O}-\mathrm{Si} \equiv+\mathrm{H}_{2} \mathrm{O} \longrightarrow 2(\equiv \mathrm{Si}-\mathrm{OH}) \quad \ldots .$. eqn $(3)$
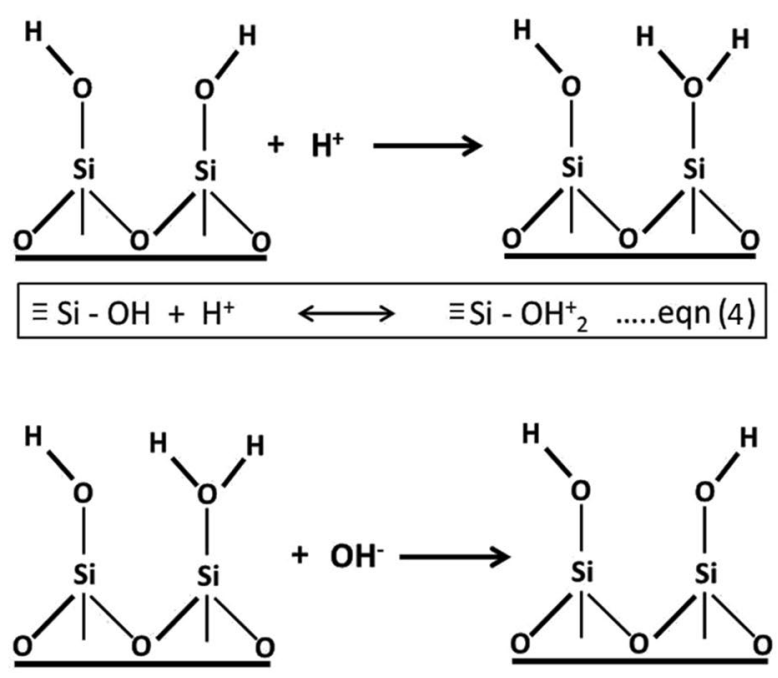

$\equiv \mathrm{Si}-\mathrm{OH}_{2}^{+}+\mathrm{OH}^{-} \longleftrightarrow$ ESi-OH $+\mathrm{H}_{2} \mathrm{O} \ldots$. ..eqn (5)

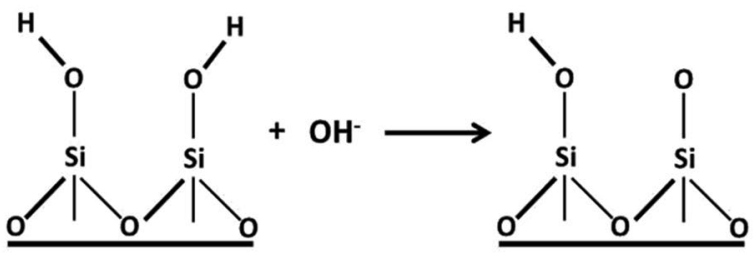

$\equiv \mathrm{Si}-\mathrm{OH}+\mathrm{OH}^{-} \longleftrightarrow \quad \equiv \mathrm{Si}-\mathrm{O}^{-}+\mathrm{H}_{2} \mathrm{O} \quad \ldots .$. eqn (6)

Fig. 16 Proposed hydrolysis steps of quartz dissolution

\section{Conclusion}

Quartz dissolution involves the weakening of siloxane ( $\mathrm{Si}-\mathrm{O}-\mathrm{Si}$ ) bonds by $\mathrm{OH}-$ ions to create defects in the quartz tetrahedron structure and form new surface ligands $\left(\mathrm{SiOH}, \mathrm{SiO}^{-}\right)$. Density function theory (DFT) calculations on $\mathrm{NaOH}$ interaction with quartz showed that the O-middle termination of $\mathrm{SiO}_{2}$ is potentially the most thermodynamically stable termination, since it has the lowest associated surface energy. Intramolecular energy was revealed to be the predominant adsorption energy in $\mathrm{NaOH}$-quartz interaction. Thus, molecular $\mathrm{NaOH}$ adsorption accounts for the transformation of the quartz structure. The DFT calculation also indicates a considerable level of variability in intramolecular adsorption energies at different sites. The adsorption energy for $\mathrm{NaOH}$ interactions with reservoir sandstone was significantly higher compared to the solitary crystal grains, which can be attributed to the isotropic deformation of a single crystal, and non-uniform deformations of adjacent grains in granular quartz of sandstone. The reduced band gap with the addition of $\mathrm{NaOH}$ indicates improved conductivity. The laboratory dissolution experiments showed the precipitations of sorbed phases, indicating that the dissolution reaction needs to be incongruent to ensure the development of etch pits, which will serve as micro- and nanopores. Quartz dissolution is also dependent on in situ mineralogy (i.e. quartz ligands, silica flakes, dissolved silica), in addition to concentration of the alkali. The DFT calculations and experimental data clearly show that exposure to $\mathrm{NaOH}$ affects the structure and reactivity of quartz, although selectively.

Open Access This article is licensed under a Creative Commons Attribution 4.0 International License, which permits use, sharing, adaptation, distribution and reproduction in any medium or format, as long as you give appropriate credit to the original author(s) and the source, provide a link to the Creative Commons licence, and indicate if changes were made. The images or other third party material in this article are included in the article's Creative Commons licence, unless indicated otherwise in a credit line to the material. If material is not included in the article's Creative Commons licence and your intended use is not permitted by statutory regulation or exceeds the permitted use, you will need to obtain permission directly from the copyright holder. To view a copy of this licence, visit http://creativecommons.org/licenses/by/4.0/.

\section{References}

Ali AM, Padmanabhan E, Baioumy HM (2017) Characterization of alkali-induced quartz dissolution rates and morphologies. Arab J Sci Eng 42(6):2501-2513

Aufort J, Aktas O, Carpenter MA, Salje EKH (2015) Effect of pores and grain size on the elastic and piezoelectric properties of quartzbased materials. Am Miner 100(5-6):1165-1171

Bagci S, Kok MV, Turskoy U (2000) Determination of formation damage in limestone reservoirs and its effect on production. J Petrol Sci Eng 28:1-12

Bickmore BR, Wheeler JC, Bater B, Nagy DL, Eggett AR (2008) Reaction pathways for quartz dissolution determined by statistical and graphical analysis of macroscopic experimental data. Geochim Cosmochim Acta 72:4521-4536

Bosak A, Krisch M, Chernyshov D (2011) New insights into the lattice dynamics of $\alpha$-quartz. Zeitschrift für Kristallographie Crystalline Materials 227(2):84-91

Brantley SL (2004) Reaction kinetics of primary rock-forming minerals under ambient conditions. In: Drever JI (ed) Surface and ground water, weathering, and soils, vol 5. Elsevier, Amsterdam, pp 73-118

Brantley SL (2008) Kinetics of mineral dissolution. In: Brantley Susan, Kubicki James, White Art (eds) Kinetics of water-rock interaction. Springer, New York

Chen YW, Cao C, Cheng HP (2008) Finding stable-quartz (0001) surface structures via simulations. Appl Phys Lett 93:181911 
Clark SJ, Segall MD, Pickard CJ, Hasnip PJ, Probert MIJ, Refson K, Payne MC (2005) First principles methods using CASTEP. Z Kristallogr 220:567-570

Degen A, Kosec M (2000) Effect of pH and impurities on the surface charge of zinc oxide in aqueous solution. J Eur Ceram Soc 20:667-673

Dove PM (1999) The dissolution kinetics of quartz in aqueous mixed cation solutions. Geochim Cosmochim Acta 63:3715-3727

Dove PM, Rimstidt JD (1994) Silica-water interactions. Rev Miner Geochem 29:259-308

Dzade NY, Roldan A, Se Leeuw NHA (2014) density functional theory study of the adsorption of Benzene on hematite $\left(\alpha-\mathrm{Fe}_{2} \mathrm{O}_{3}\right)$ surfaces. Minerals 4:89-115

Escamilla-Roa E, Huertas F, Hernández-Laguna A, Sainz-Díaz C (2017) A DFT study of the adsorption of glycine in the interlayer space of montmorillonite. Phys Chem Chem Phys 19:14961-14971

Eschrig H (2003) The fundamentals of density functional theory. Teubner. Springer, Berlin

Goumans TPM, Wander A, Brown WA, Catlow CRA (2007) Structure and stability of the (001)-quartz surface. Phys Chem Chem Phys 9:2146-2152

Hornof V, Neale GH, Gholam-Hosseini M (2000) Effects of flow rate and alkali-to-acid ratio on the displacement of acidic oil by alkaline solutions in radial porous media. J Colloid Interface Sci 231:196-198

Labrid J, Duquerroix JP (1991) Thermodynamic and kinetic aspects of the dissolution of quartz-kaolinite mixtures by alkalis. Revue de L'Institut Francais du Pétrole 46:41-59

Lasaga AC, Luttge A (2001) Variation of crystal dissolution rate based on a dissolution stepwave model. Science 291:2400-2404

Nangia S, Garrison BJ (2008) Reaction rates and dissolution mechanisms of quartz as a function of $\mathrm{pH}$. J Phys Chem A 112:2027-2033

Nangia S, Washton NM, Mueller KT, Kubicki JD, Garrison BJ (2007) Study of a family of 40 hydroxylated $\beta$-cristobalite surfaces using empirical potential energy functions. J Phys Chem C 111:5169

Nilges MJ, Pan Y, Mashkovtsev RI (2009) Radiation-induced defects in quartz. III. Single-crystal EPR, ENDOR and ESEEM study of a peroxyradical. Phys Chem Miner 36:61-73

Pelmenschikov A, Strandh H, Pettersson LGM, Leszczynski J (2000) Lattice resistance to hydrolysis of $\mathrm{Si}-\mathrm{O}-\mathrm{Si}$ bonds of silicate minerals: ab initio calculations of a single water attack onto the (001) and (111) b-cristobalite surfaces. J Phys Chem B 104:5779-5783

Pertsev NA, Salje EKH (2000) Thermodynamics of pseudoproper and improper ferroelastic inclusions and polycrystals: effect of elastic clamping on phase transitions. Phys Rev B 61:902-908

Pollard PJ, Taylor RG, Tate NM (1989) Textural evidence for quartz and feldspar dissolution as a mechanism of formation for Maggs Pipe, Zaaiplaats tin mine, South Africa. Miner Depos 24:210

Qiu YQ, Cui WY, Li LJ, Ye JJ, Wang J, Zhang Q (2017) Structural, electronic properties with different terminations for fluorapatite
(001) surface: a first-principles investigation. Comput Mater Sci 126:132-138

Rimstidt JD (2015) Rate equations for sodium catalyzed quartz dissolution. Geochim Cosmochim Acta 167:195-204

Schott J, Oelkers EH (1995) Dissolution and crystallization rates of silicate minerals as a function of chemical affinity. Pure Appl Chem 67:903-910

Smith JV, Steele IM (1984) Chemical substitution in the silica polymorphs. Neues Jahrbuch für Geologie und Paläontologie, Monatsh, pp 137-44

Vanderbilt D (1990) Soft self-consistent pseudopotentials in a generalized eigenvalue formalism. Phys Rev B 41:7892-7895

Wallace AF, Gibbs GV, Dove PM (2010) Influence of ion-associated water on the hydrolysis of $\mathrm{Si}-\mathrm{O}$ bonded interactions. J Phys Chem A 114:2534-2542

Wander MCF, Clark AE (2008) Structural and dielectric properties of quartz-water interfaces. J Phys Chem C 112:19986-19994

Wang L, Zhang G, Ge JJ, Li G, Zhang J, Ding B (2010) Preparation of microgel nanospheres and their application in EOR. In: CPS/SPE, Society of Petroleum Engineers, China, Beijing

Wang X, Zhang Q, Li X, Ye J, Li L (2018) Structural and electronic properties of different terminations for quartz (001) surfaces as well as water molecule adsorption on it: a first-principles study. Minerals 8:58

White AF, Brantley SL (eds) (1995) Chemical weathering rates of silicate minerals. Rev Mineral. Mineralogical Society of America

White AF, Bullen TD, Schulz M, Blum AE, Huntington TG, Peters NE (2001) Differential rates of feldspar weathering in granitic regoliths. Geochim Cosmochim Acta 65:847-869

Xiao Y, Lasaga AC (1996) Ab initio quantum mechanical studies of the kinetics and mechanisms of quartz dissolution: $\mathrm{OH}$ catalysis. Geochim Cosmochim Acta 60:2283-2295

Yang JJ, Wang EG (2006) Water adsorption on hydroxylated alphaquartz (0001) surfaces: from monomer to flat bilayer. Phys Rev B 73:035406

Yang J, Meng S, Xu LF, Wang EG (2004) Ice tessellation on a hydroxylated silica surface. Phys Rev Lett 92(14):6102-6104

Yanina SV, Rosso KM, Meakin P (2006) Defect distribution and dissolution morphologies on low-index surfaces of $\alpha$-quartz. Geochim Cosmochim Acta 70:1113-1127

Zhang ST, Liu Y (2014) Molecular-level mechanisms of quartz dissolution under neutral and alkaline conditions in the presence of electrolytes. Geochem J 48:189-205

Zubko P, Catalan G, Tagantsev AK (2013) Flexoelectric effect in solids. Annu Rev Mater Res 43:387-421

Publisher's Note Springer Nature remains neutral with regard to jurisdictional claims in published maps and institutional affiliations. 